\title{
Impact of Climate Change on Vegetation Distribution and Net Primary Productivity of Forests of Himalayan River Basins: Brahmaputra, Koshi and Indus
}

\author{
A. Chaitra', S. Upgupta1, L. D. Bhatta' ${ }^{2}$ J. Mathangi', D. S. Anitha1, K. Sindhu', Vidya Kumar', \\ N. K. Agrawal2, M. S. R. Murthy², F. Qamar², Indu K. Murthy', J. Sharma1, R. K. Chaturvedi1, \\ G. Bala ${ }^{3}$, N. H. Ravindranath' \\ ${ }^{1}$ Centre for Sustainable Technologies, Indian Institute of Science, Bengaluru, India \\ ${ }^{2}$ International Centre for Integrated Mountain Development (ICIMOD), Kathmandu, Nepal \\ ${ }^{3}$ Divecha Centre for Climate Change, Centre for Atmospheric Sciences, Indian Institute of Science, Bengaluru, India \\ Email: *indumurthy@iisc.ac.in
}

How to cite this paper: Chaitra, A., Upgupta, S., Bhatta, L.D., Mathangi, J., Anitha, D.S., Sindhu, K., Kumar, V., Agrawal, N.K., Murthy, M.S.R., Qamar, F., Murthy, I.K., Sharma, J., Chaturvedi, R.K., Bala, G. and Ravindranath, N.H. (2018) Impact of Climate Change on Vegetation Distribution and Net Primary Productivity of Forests of Himalayan River Basins: Brahmaputra, Koshi and Indus. American Journal of Climate Change, 7, 271-294. https://doi.org/10.4236/ajcc.2018.72018

Received: January 16, 2018

Accepted: June 17, 2018

Published: June 20, 2018

Copyright ( $\odot 2018$ by authors and Scientific Research Publishing Inc. This work is licensed under the Creative Commons Attribution International License (CC BY 4.0).

http://creativecommons.org/licenses/by/4.0/

c) (i) Open Access

\begin{abstract}
The impacts of climate change in terms of forest vegetation shifts and Net Primary Productivity (NPP) changes are assessed for Brahmaputra, Koshi and Indus river basins for the mid (2021-2050) and long (2071-2100) terms for RCP4.5 and RCP8.5 scenarios. Two Dynamical Global Vegetation Models (DGVMs), Integrated BIosphere Simulator (IBIS) and (Lund Postdam and Jena (LPJ), have been used for this purpose. The DGVMs are driven by the ensemble mean climate projections from 5 climate models that contributed to the CMIP5 data base. While both DGVMs project vegetation shifts in the forest areas of the basins, there are large differences in vegetation shifts projected by IBIS and LPJ. This may be attributed to differing representation of land surface processes and to differences in the number of vegetation types (Plant Functional Types) defined and simulated in the two models. However, there is some agreement in NPP changes as projected by both IBIS and LPJ, with IBIS mostly projecting a larger increase in NPP for the future scenarios. Despite the uncertainties with respect to climate change projections at river basin level and the differing impact assessments from different DGVMs, it is necessary to assess the "vulnerability" of the forest ecosystems and forest dependent communities to current climate risks and future climate change and to develop and implement resilience or adaptation measures. Assessment of the "vulnerability" and designing of the adaptation strategies could be undertaken for all the forested grids where both IBIS and LPJ project vegetation shifts.
\end{abstract}




\section{Keywords}

Climate Change, Forests, Himalayan River Basins, Impacts, NPP Change, Forest Type Shift

\section{Introduction}

Climate change is of particular relevance to policymaking because the inexorable rise in the average global temperature is expected to change the hydrological cycle, a consequence that will have multiple impacts on natural resources (e.g. forestry and agriculture). These changes will alter the magnitude, timing, and intensity of a region's prevailing precipitation pattern (e.g. whether snow or rainfall) and affect the regional hydrology.

Climate is one of the most important determinants of vegetation patterns globally and has significant influence on the distribution, structure and ecology of forests [1]. Several climate-vegetation studies have shown that climatic regimes determine specific plant communities or functional types in any region [2]. It is therefore logical to assume that changes in climate would alter the distribution of forest ecosystems. Based on a range of vegetation modelling studies, there are indications of potential forest dieback towards the end of this century and beyond, especially in tropics, boreal and mountain regions [3] [4] [5].

According to the IPCC [6], "for many natural systems on land and in the ocean, new or stronger evidence exists for substantial and wide-ranging climate change impacts" and the model-based projections indicate large-scale forest dieback and loss of biodiversity. Non-climate stressors like, unsustainable dependence of communities on forests, land-use change, and forest management practices associated with harvesting of wood and other forest products and raising of single-species plantations would further exacerbate the adverse impacts under climate change [6]. Climate change will be the dominant stressor on terrestrial ecosystems "in the second half of the $21^{\text {st }}$ century, especially under RCP6.0 and 8.5" [6], and up to 2040 non-climatic stressors such as land-use change and pollution "will continue to dominate threats to most freshwater ecosystems and most terrestrial ecosystems" [6].

A modelling study for India [7] indicated that $30.6 \%$ and $45 \%$ of the forest areas are likely to experience shift in forest types for the projected climate change under A1B scenario in the mid (2030s) and long (2080s) term, respectively. Impacts of climate change on forests have severe implications for the people who depend on forest resources for their livelihoods. Thus it is necessary to assess the likely impacts of projected climate change on primary forests and afforested plantation areas, and develop and implement adaptation strategies to enhance the resilience of forests to climate change. The present study investigates the projected impacts of climate change on forests in river basins of Brahmaputra, Koshi and Upper Indus using two dynamic global vegetation models (DGVM's) 
for the mid-term (2021-2050) and long-term (2071-2100) periods. It specifically assesses the shifts in vegetation types and changes in NPP (net primary productivity).

The overall objective of the study is to assess the impact of projected climate change on forest ecosystems of the 3 river basins of Himalayan region.

To assess the impact of climate change on forest ecosystems of the three river basins using the latest CMIP5 climate model projections and two dynamic global vegetation models.

To assess the impact of climate change on vegetation shifts and NPP of the forest ecosystems of the three river basins.

In this study, the investigation is limited to only vegetation shifts and NPP since these two variables are more fundamental to ecosystems and have been also validated by previous studies [7] [8]. Carbon stocks have not been analysed because it is challenging to validate model simulated carbon stocks as observations (of biomass and soil carbon) are lacking.

\section{Study Area}

Climate change assessment is carried out for the 3 river basins of Himalayan Region namely: Brahmaputra, Koshi and Upper Indus.

Brahmaputra: The Brahmaputra takes its birth in the Kanglung Kang Glacier near the Kailash range of Himalayas located in the south-western part of the Tibetan plateau at an elevation of $5300 \mathrm{~m}\left(82^{\circ} 10^{\circ} \mathrm{E}\right.$ and $\left.30^{\circ} 30^{\prime} \mathrm{N}\right)$ near Konggyu Tso Lake. The Brahmaputra River traverses a distance of $2880 \mathrm{~km}$ through three countries, namely, China, India, and Bangladesh, before joining the Bay of Bengal. The catchment area of the river falls in four countries. Although the main river does not flow through the Kingdom of Bhutan, $96 \%$ of Bhutan's area falls under this basin. The basin lies between $23^{\circ} \mathrm{N}$ to $32^{\circ} \mathrm{N}$ latitude and $82^{\circ} \mathrm{E}$ to $97^{\circ} 50^{\prime} \mathrm{E}$ longitude. In India, the Brahmaputra basin covers parts of six states: Arunachal Pradesh, Assam, Nagaland, Meghalaya and West Bengal and the whole of Sikkim. The cultivated area of the basin is around 12.15 Mha. About $30 \%$ of the Brahmaputra river basin is covered by forest. Tropical semi evergreen forest is the dominant observed current forest type, which covers $22.5 \%$ of total area of the basin as shown in Figure 1. This forest type covers lower Dibang valley, Lohit, Anjaw and parts of Tinsukia. Medium dense forest dominates as shown in Figure 2, and is spread over north-eastern parts of the basin. The remaining is covered by open, very dense and non-forest areas.

Koshi river basin: Koshi River drains the northern slopes of the Himalayas in Tibet Autonomous Region and the southern slopes in Nepal. The Koshi River is also known as Saptakoshi. It is $720 \mathrm{~km}$ (450 mi) long and drains an area of about $61,000 \mathrm{~km}^{2}(24,000 \mathrm{sq} \mathrm{mi})$ in Tibet, Nepal and Bihar. The Koshi basin is bounded on the north by the Himalayas, on the east by Mahananda basin, on the west by the BurhiGandak basin and on the south by the river Ganga. The basin in Indian Territory extends over severs districts of Bihar: Saharsa, Purnea, Khagaria, Madhubani, Sitamarhi, Muzaffarpur and Darbhanga. The more important 


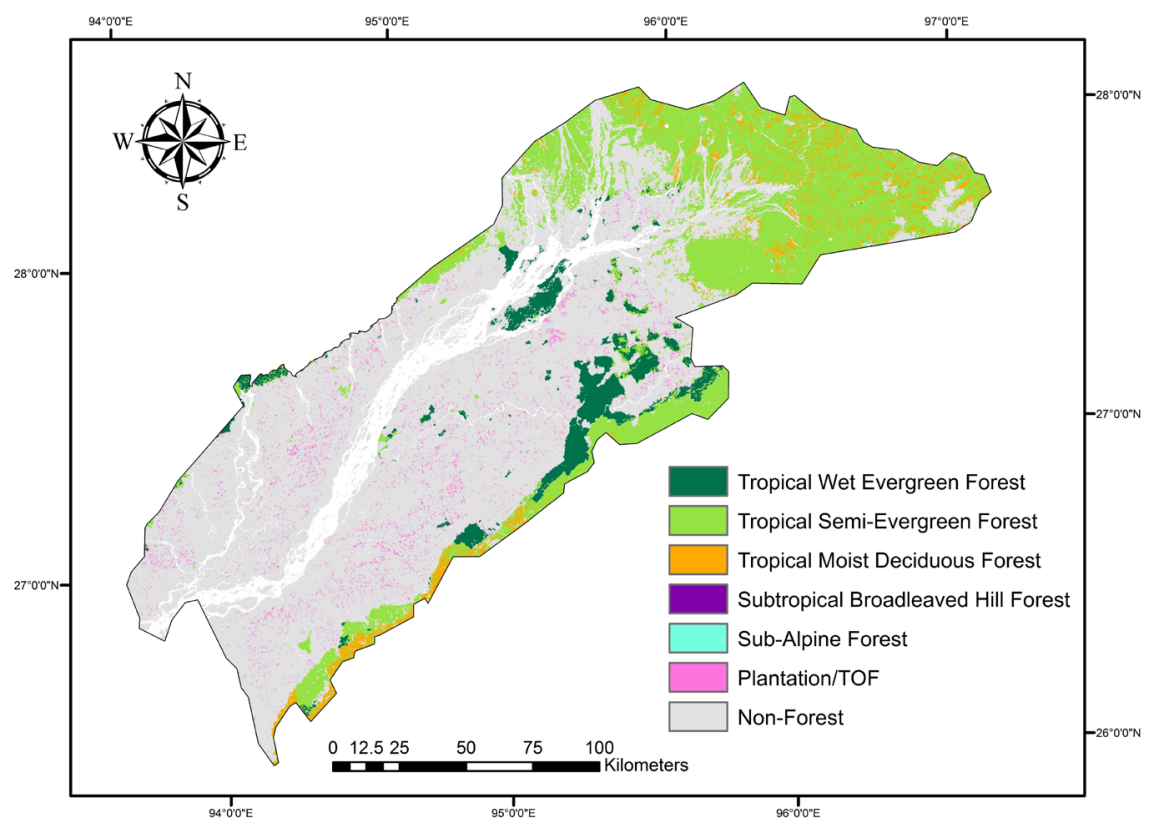

Figure 1. Forest type distribution in the Brahmaputra river basin.

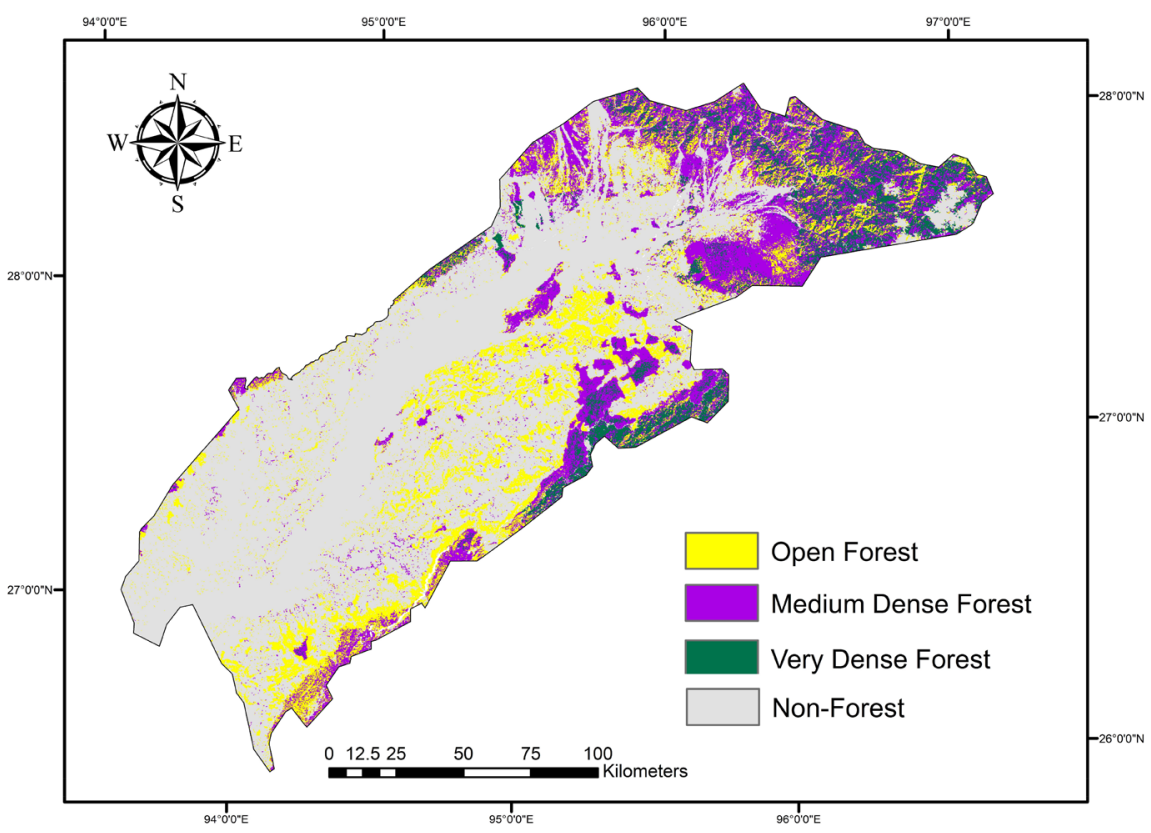

Figure 2. Forest density distribution in the Brahmaputra river basin.

rivers in this basin are Koshi (main stem), Kamla Balan Adhwara Group of rivers and Bagmati. Koshi river basin has broadly two types of forests; Broadleaved and Coniferous (Figure 3). The proportion of area covered by dense forest is less in this basin. Dense broadleaved forest is spread along southern part of the forested area in the basin, with small chunks in the eastern region. Dense coniferous forest covers the middle and northern region. Also we find the sparse coniferous and broadleaved forest in the central part of the region. Dense broadleaved forest covers major portion of forested area accounting for $32 \%$ of the region. 


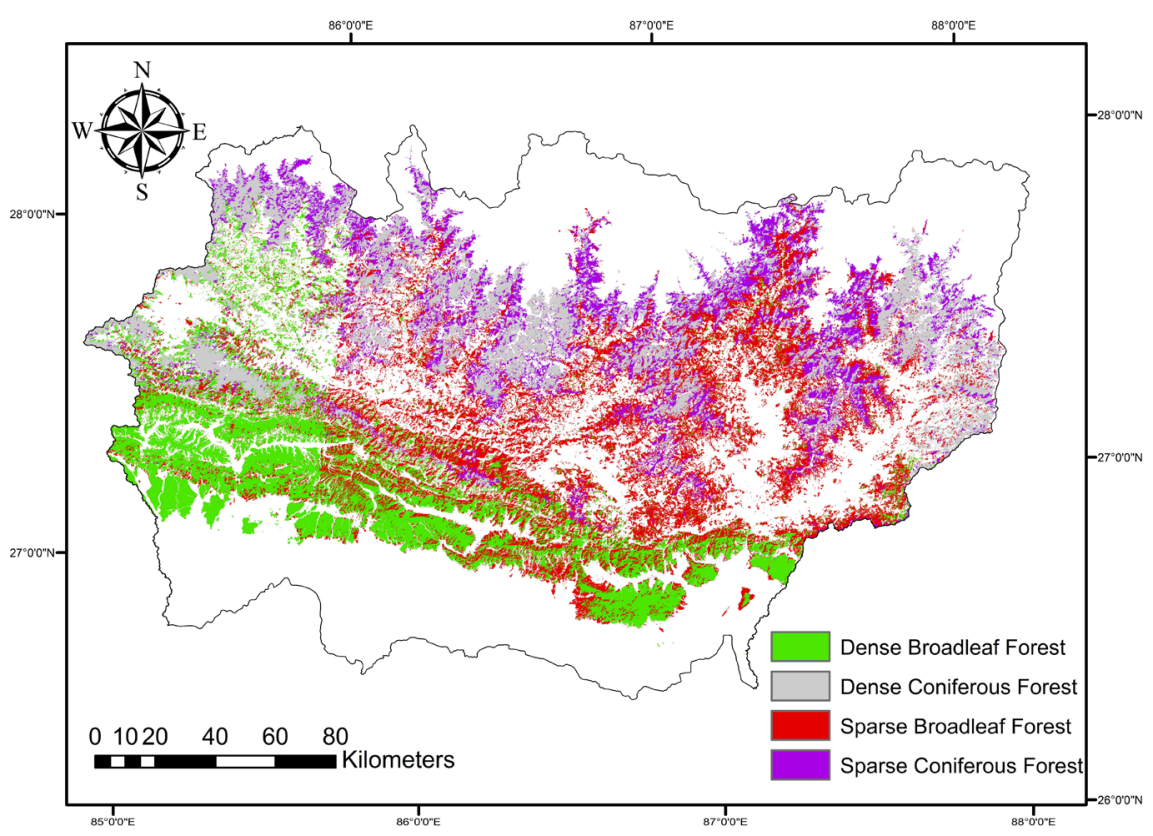

Figure 3. Forest type distribution in the Koshi river basin.

Upper Indus basin: The trans-boundary Indus river basin has a total area of 1.12 million $\mathrm{km}^{2}$ distributed between Pakistan (47 percent), India (39 percent), China (8 percent) and Afghanistan (6 percent). The main river originates at Lake Ngangla Rinco on the Tibetan Plateau in China and includes the flow of tributaries Ravi, Beas, Sutlej, Swat, Chitral, Gilgit, Hunza, Shigar, Shyok, Indus, Shingo, Astor, Jhelum, Chenab, and Kabul draining parts of Afghanistan, China, India, and Pakistan. The Indus river basin stretches from the Himalayan Mountains in the north to the dry alluvial plains of Sindh province in Pakistan in the south and finally flows out into the Arabian Sea. The drainage area lying in India is approximately $440,000 \mathrm{~km}^{2}$, nearly 14 percent of the total area of the country, in the States of Jammu and Kashmir, Himachal Pradesh, Punjab, Rajasthan, Haryana and Chandigarh. Approximately 300 million people are estimated to live in the Indus basin. The basin is the predominant provider of water for agriculture, energy production, industrial use, and human consumption for the people living in the basin. Most of the forest in Indus basin is concentrated in the south-west portion of the basin (Figure 4). The basin has 3 types of vegetation, namely; Broadleaf, Conifer and Mixed forest. All types have different density spread over the basin. The major portion of forest is covered by dense conifer forest, accounting up to $38.5 \%$ of forest density of the basin. Sparse conifer forest covers $27 \%$. The dense and sparse broadleaf forest covers only $6 \%$ of the basin. The extent of catchment areas and major types of forest vegetation in the three basins are summarized in Table 1 .

\section{Methods and Models}

The impact of climate change on forests is assessed by identifying shifts in boundary of forest types and changes in NPP. This assessment is based on the 


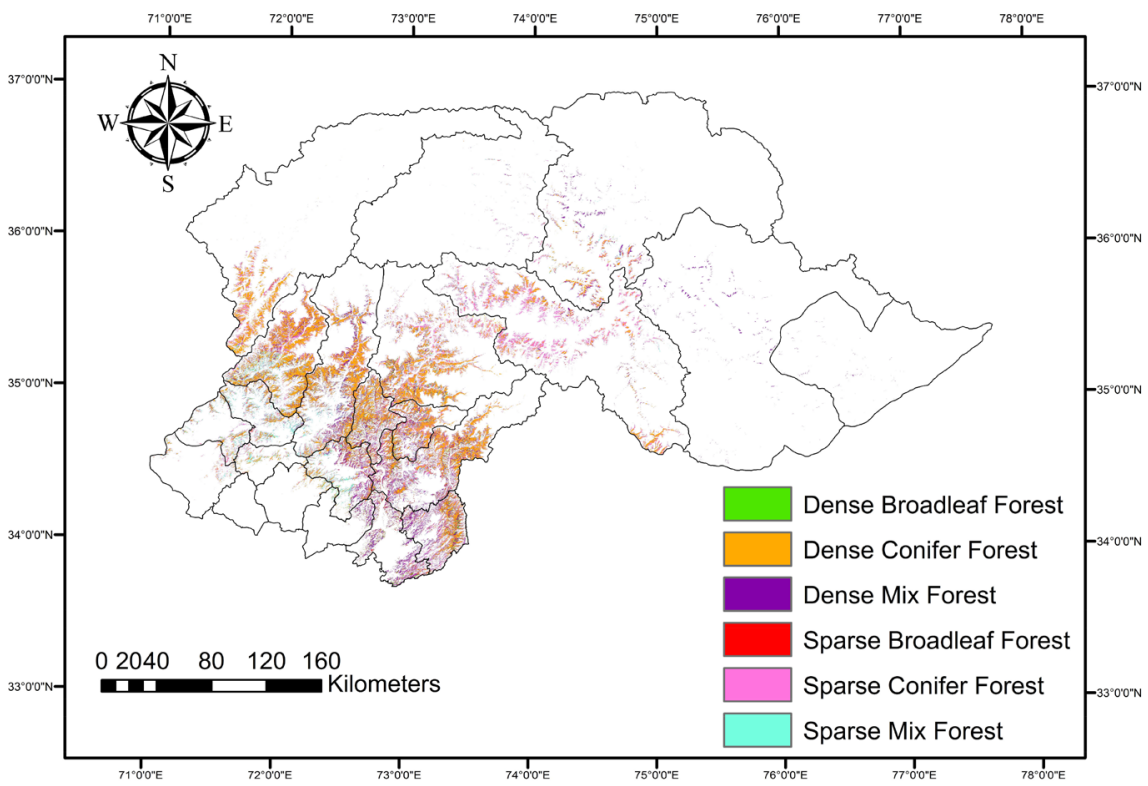

Figure 4. Forest type distribution in the Upper Indus river basin.

Table 1. Countries, catchment area and dominant forest types of the three river basins.

\begin{tabular}{cccc}
\hline Features & Brahmaputra & Koshi & Indus \\
\hline Countries & India, China, Bangladesh & India, Tibet, Nepal & $\begin{array}{c}\text { India, Pakistan, China, } \\
\text { Afghanistan }\end{array}$ \\
Catchment Area & $580,000 \mathrm{sq.km}$ & $61,000 \mathrm{sq} . \mathrm{km}$ & 1.12 million sq.km \\
Major Forest type & $\begin{array}{c}\text { Tropical semi-evergreen } \\
\text { forest }\end{array}$ & Broadleaved forest & Conifer forest \\
\hline
\end{tabular}

spatial distribution of vegetation (forest) types and NPP as simulated by two dynamic global vegetation models (DGVMs); Integrated Biosphere Simulator (IBIS) and Lund Potsdam Jena Model (LPJ). We used two DGVMs to provide an estimate of the uncertainty, robustness and hence the reliability of the simulations. These two models have been validated for India by previous studies at the Indian Institute of Science [7] [8].

\subsection{Climate Change Projections and Scenarios}

Climate projections for impact assessment are obtained from CMIP5 models. Even though large number of GCMs (General Circulation Models) or ESMs (Earth System Models) is available only 5 ESMs which provide all climate variables required for running the DGVMs are selected (Table 2). An ensemble of those 5 ESMs was developed for running the DGVMs. Among the 4 RCPs (Representative Concentration Pathways), RCP4.5 and RCP8.5 were selected since these two scenarios were available for all 5 models.

- Climate models: CMIP5 (Coupled Model Inter-comparison Project 5)

- Ensemble size: 5 models

- Period of projection in this study: 2021-2050 (Mid-term) and 2071-2100 
(Long-term)

- Resolution of re-gridded data: $50 \mathrm{~km} \times 50 \mathrm{~km}$

- RCPs: 4.5 and 8.5

\subsection{DGVMs Used for Impact Assessment}

Two Dynamic Global Vegetation Models (DGVMs) have been used for assessing the impact of climate change on the Himalayan river basins as it would provide an estimate of the uncertainty, robustness and hence the reliability of the projections on future changes in vegetation characteristics. If a given forested grid is shown to be impacted by both the DGVMs, then the confidence would be very high. Though more DGVMs would be desirable for robust estimates, we are constrained by resource limitations in this study.

IBIS and LPJ have many differences in their inputs, process representation, functionality and outputs. The major difference lies in the vegetation types represented in the two models. IBIS defines 15 vegetation types, whereas LPJ defines only 9 vegetation types (Table 3 ). Most of the vegetation types of IBIS are found

Table 2. CMIP5 climate models used for generating the ensemble mean climate.

\begin{tabular}{ccc}
\hline S1. No & Model name & Modeling centre \\
\hline 1 & BCC-CSM1-1 & Beijing Climate Centre, China, Meteorological Administration \\
2 & IPSL-CM5A-LR & Institut Pierre-Simon Laplace, France \\
3 & MIROC-ESM & Japan Agency for Marine-Earth Science and Technology \\
4 & MIROC-ESM-CHEM & Japan Agency for Marine-Earth Science and Technology \\
5 & MIROC5 & Japanese research community \\
\hline
\end{tabular}

Table 3. Plant Functional Types (PFTs) represented in IBIS and LPJ Models.

\begin{tabular}{cc}
\hline IBIS Plant Functional Types & LPJ Plant Functional Types \\
\hline Tropical Broadleaf Evergreen Trees & Tropical Broadleaved Evergreen_Tree \\
Tropical Broadleaf Drought-Deciduous Trees & Tropical Broadleaved Raingreen_Tree \\
Warm-Temperate Broadleaf Evergreen Trees & Temperate Needleleaved Evergreen Tree \\
Temperate Conifer Evergreen Trees & Temperate Broadleaved Evergreen_Tree \\
Temperate Broadleaf Cold-Deciduous Trees & Temperate Broadleaved Summergreen_Tree \\
Boreal Conifer Evergreen Trees & Boreal NeedleleavedEvergreen_Tree \\
Boreal Broadleaf Cold-Deciduous Trees & Boreal Broadleaved Summergreen_Tree \\
Boreal Conifer Cold-Deciduous Trees & C3 Perennial Grass \\
Evergreen Shrubs & C4 Perennial Grass \\
Cold-Deciduous Shrubs & \\
Warm (C4) Grasses & \\
Cool (C3) Grasses & \\
Tundra & \\
Polar Desert & \\
\hline
\end{tabular}


in India. Because of this difference it is likely that there could be differences between the results of these two models.

IBIS (Integrated Biosphere Simulator): The dynamic vegetation model IBIS is designed around a hierarchical, modular structure [9]. The model consists of four modules namely 1) Land surface module, 2) Vegetation phenology module, 3) Carbon balance module and 4) Vegetation dynamics module. These modules, though operating at different time steps, are integrated into a single physically consistent model that may be directly incorporated within AGCMs (Atmospheric General Circulation models) for receiving climate data. For example, IBIS is currently incorporated into two AGCMs namely GENESIS-IBIS [10] and CCM3-IBIS [11]. In this study, we provide climate date for driving IBIS and hence IBIS is run in an "offline mode" here.

Lund Potsdam and Jena (LPJ): Lund Potsdam and Jena (LPJ) model is developed by Potsdam Institute for Climate Impact Research (PIK), Germany. LPJ is a dynamic global model of vegetation biogeography and vegetation/soil biogeochemistry. Driven by climate data, soil and atmospheric information, it dynamically computes spatially explicit transient vegetation composition in terms of plant functional groups, and their associated carbon and water budgets. The LPJ model combines process-based, large-scale representations of terrestrial vegetation dynamics and land-atmosphere carbon and water exchanges in a modular framework. Features include feedback through canopy conductance between photosynthesis and transpiration, and interactive coupling between these fast processes and other ecosystem processes, including resource competition, tissue turnover, population dynamics, soil organic matter and litter dynamics, and fire disturbance.

Figures 5(a)-(c) shows the PFTs as simulated by IBIS and LPJ in the baseline climate in Brahmaputra (a), Indus (b) and Koshi (c) river basins. There is a high degree of agreement between IBIS and LPJ in Brahmaputra and Indus river basis but the agreement is not strong in Koshi river basin.

There are several modeling studies in literature that infer increased water use efficiency by simulating reduced plant transpiration and increased runoff for elevated $\mathrm{CO}_{2}$ levels. Both IBIS and LPJ have explicit representation for increased water use efficiency for elevated $\mathrm{CO}_{2}$ by parameterizing stomatal conductance as a function of atmospheric $\mathrm{CO}_{2}$ concentration. However, in this study, runoff and canopy transpiration has not been generated from the models. Further, the focus of this study is on the impacts climate change on the dynamics of vegetation and forest productivity, and hence the projections of transpiration and runoff have not been assessed.

Data requirements for IBIS and LPJ: LPJ requires 3 climate variables namely, temperature, precipitation and cloudiness (Table 4). IBIS requires 8 climate variables namely temperature, precipitation, cloudiness, relative humidity, temperature range, wet days, wind speed and delta $\mathrm{T}$ (minimum temperature ever recorded at a particular location minus average temperature of the coldest month). 


\section{Impact of Climate Change on Forest Ecosystems of Himalayan River Basins}

In this section, the impacts of climate change on forest ecosystems in the Brahmaputra, Indus and Koshi river basins are presented.
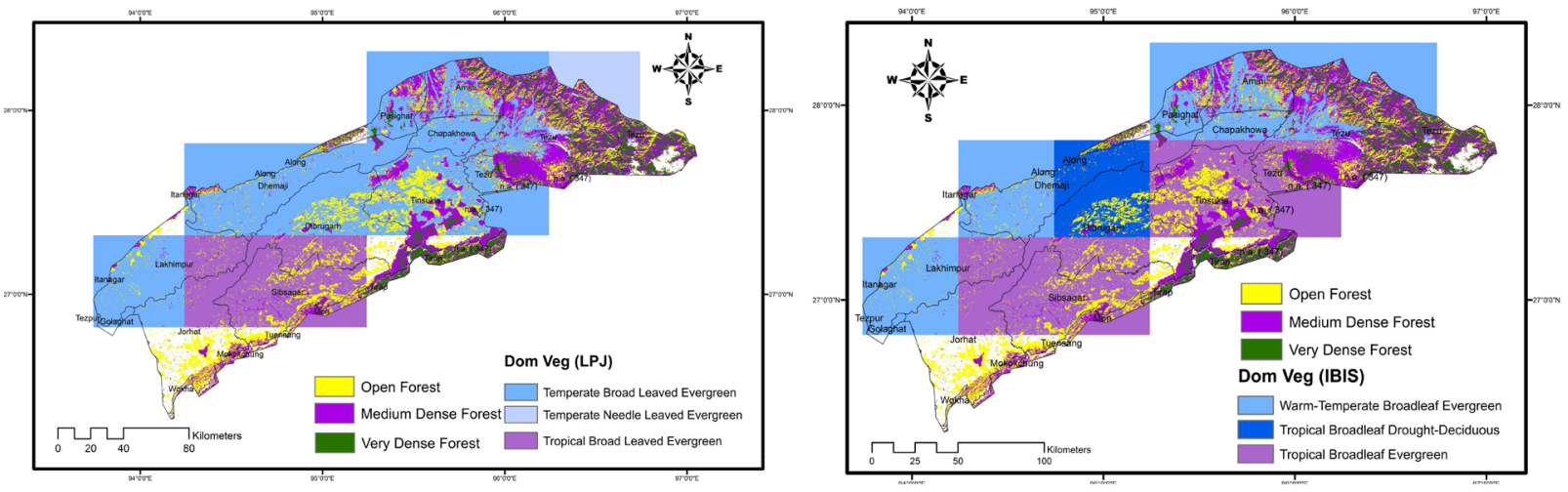

(a)
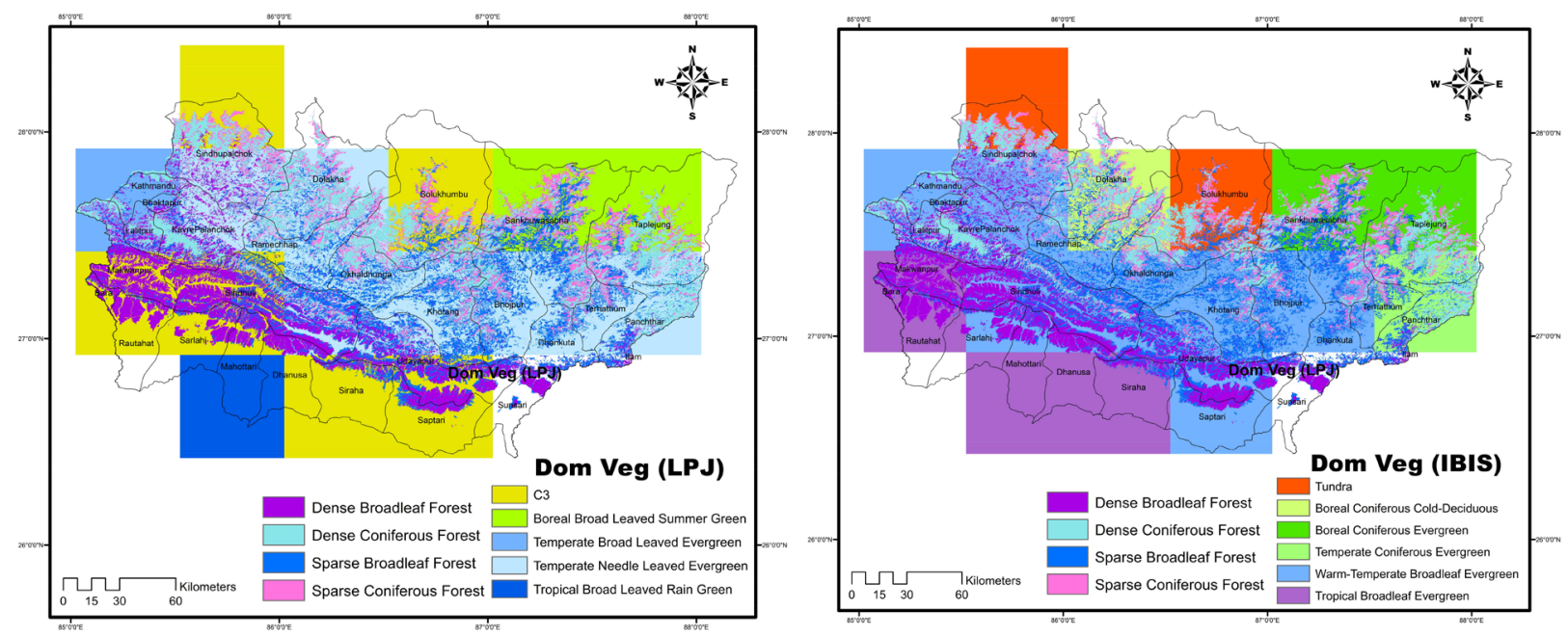

(b)
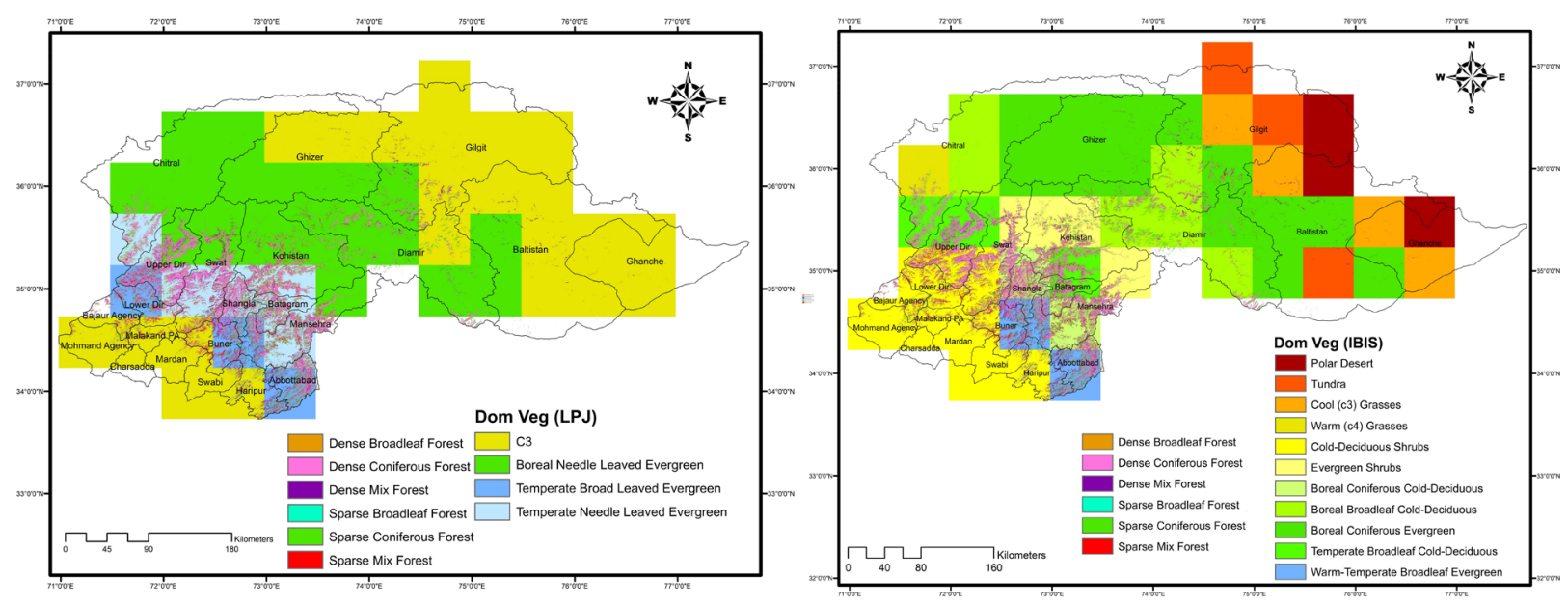

(c)

Figure 5. (a)-(c) PFTs simulated by IBIS and LPJ in the baseline climatefor the Brahmaputra, Indus and Koshi river basins. 
Table 4. Variables used to drive IBIS and LPJ model.

\begin{tabular}{cccc}
\hline \multicolumn{2}{c}{ IBIS } & \multicolumn{2}{c}{ LPJ } \\
\hline Climate variables & Other variables & Climate variables & Other variables \\
Temperature & $\mathrm{CO}_{2}$ value & Temperature & $\mathrm{CO}_{2}$ value \\
Precipitation & Initial Vegetation & Precipitation & Soil data \\
Cloudiness & Clay percentage & Cloud cover & Grid data \\
Temperature range & Sand percentage & & \\
Wet days & Land mask & & \\
Wind speed & Topography & & \\
Relative humidity & & & \\
deltaT & & & \\
\hline
\end{tabular}

\subsection{Brahmaputra River Basin}

In this study, the impact of climate change is assessed by comparing the distribution of forest types under baseline (current climate) scenario with that under climate change scenarios. The number of forested grid points belonging to different forest types undergoing change under the climate change scenarios is compared. We assume that the climate change impact in the form of vegetation shift means that the future or projected climate is not suitable for the existing forest types, species, and biodiversity, leading to potential forest dieback and loss of biodiversity.

One should be cautious in interpreting vegetation shifts because vegetation changes take place over an ecological continuum in the real world but vegetation and climate are represented on discrete grid points in the models. Therefore, both climate and vegetation changes are not continuum in the models. This is especially true for land surface processes in the model where the complex heterogeneity of the real land surface could not be realistically represented on a discrete grid.

Further, since model simulated limited number of vegetation types in the baseline climate state may not exactly match the numerous FSI defined vegetation types at the model grid scale, we focus only on identifying the grid points in the model where a vegetation shift is projected. Similarly, in order to address the productivity issue, the study relies on the model projected changes in NPP. Normally any large degree of NPP changes goes in hand with changes in water availability or water use efficiency. However, this study does not include assessment of hydrological parametersas the same has not been generated by the models.

\subsubsection{Forest Vegetation Shift under RCP 4.5 and 8.5 in the Mid-Term}

Figures 6(a)-(d) show the grid points projected to undergo change in forest type in the mid-term and long-term under RCP 4.5 and 8.5 as simulated by IBIS and LPJ. IBIS model projects vegetation shift in central part of Brahmaputra river basin covering districts of Dibrugarh and Dhemaji in both RCPs. These grid 


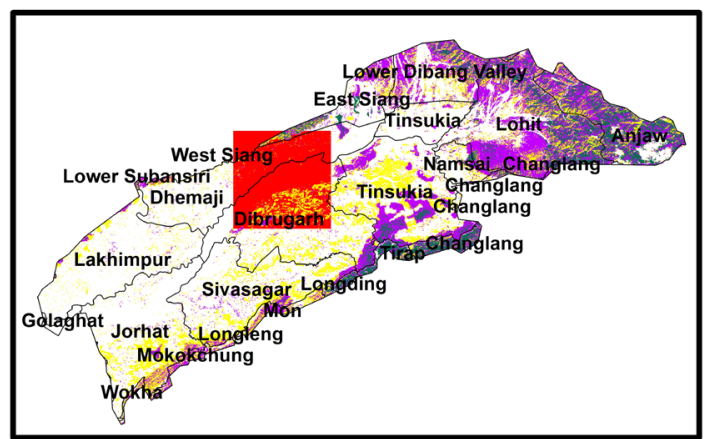

(a)
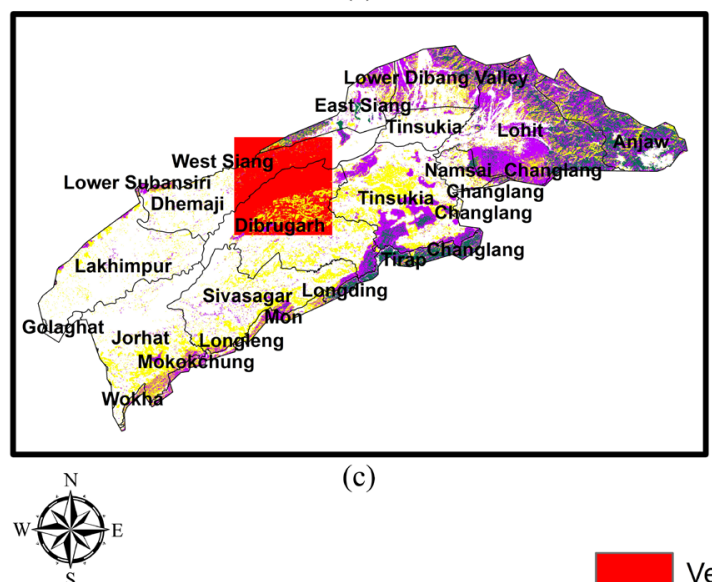

(c)

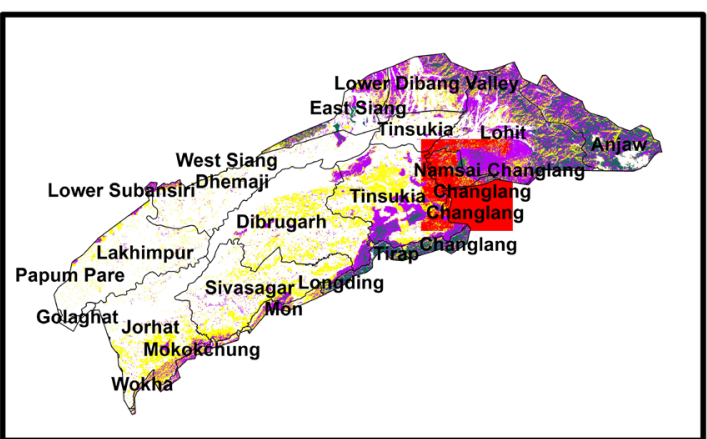

(b)

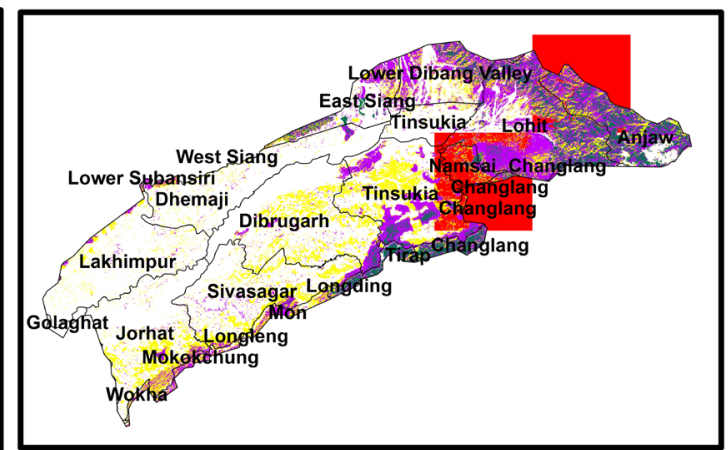

(d)

Vegetation Shift Open Forest

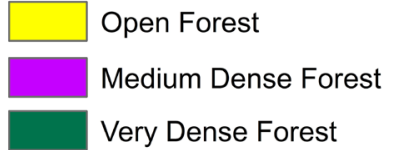

Figure 6. (a)-(d) Vegetation shifts in the mid-term (2021-2050) as simulated by IBIS and LPJ under RCP 4.5 and 8.5 scenarios for the Brahmaputra river basin.

points are covered by low crown density forest of Tropical semi-evergreen and plantations.

LPJ does not show changes in forest types in RCP4.5 while in RCP 8.5 LPJ shows vegetation change in north east part of the basin covering Lohit, Anjaw and Tinsukia districts. This area mostly consists of tropical semi-evergreen and tropical moist-deciduous forests with medium dense crown cover.

\subsubsection{Forest Vegetation Shift under RCP 4.5 and 8.5 in the Long-Term}

Figures $7(a)-(d)$ show the grid points projected to undergo change in forest type in the long-term (2071-2100) under the two RCPs as simulated by the two DGVMs. IBIS model projects vegetation shift in only one grid point in central part of Brahmaputra river basin covering districts of Dibrugarh and Dhemaji in both the RCP scenarios. This area is covered by tropical semi-evergreen forest and plantations.

LPJ projects vegetation shift in grid points covering districts of Anjaw, Lohit, Dibrugarh, Dhemaji, Jorhat, Sivasagar and Tinsukia districts for both the RCP scenarios. Anjaw and Lohithave tropical semi-evergreen forest while Tinsukia has Tropical wet evergreen forest and plantations. Sivasagar, Dibrugarh, parts of Jorhat and Dhemaji are covered mostly with plantations. 


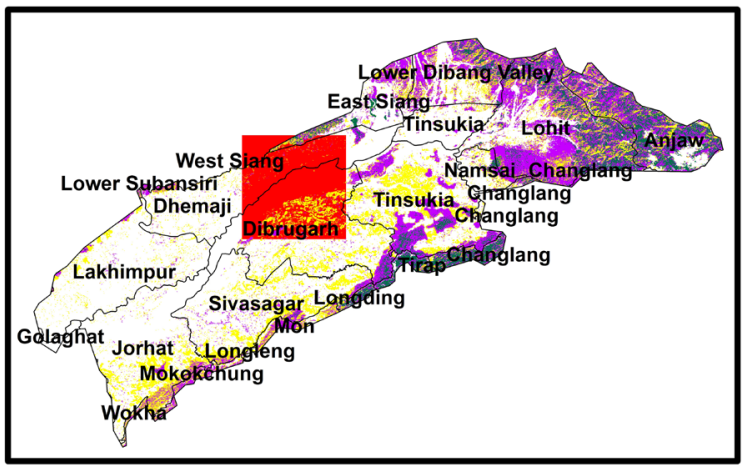

(a)

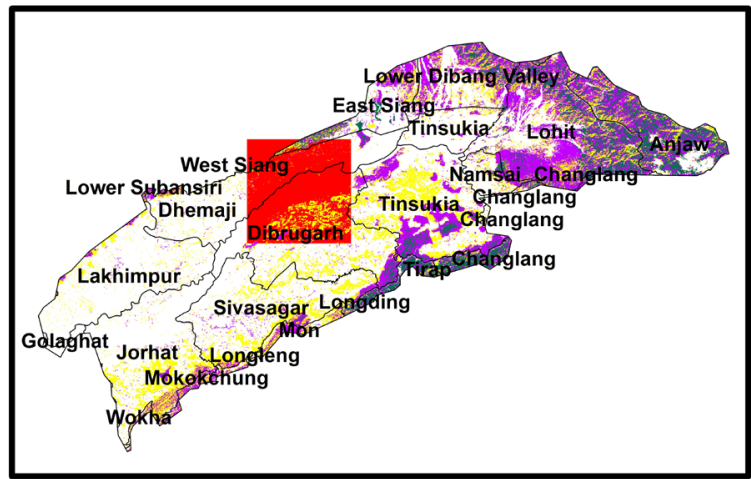

(c)

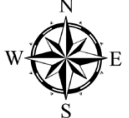

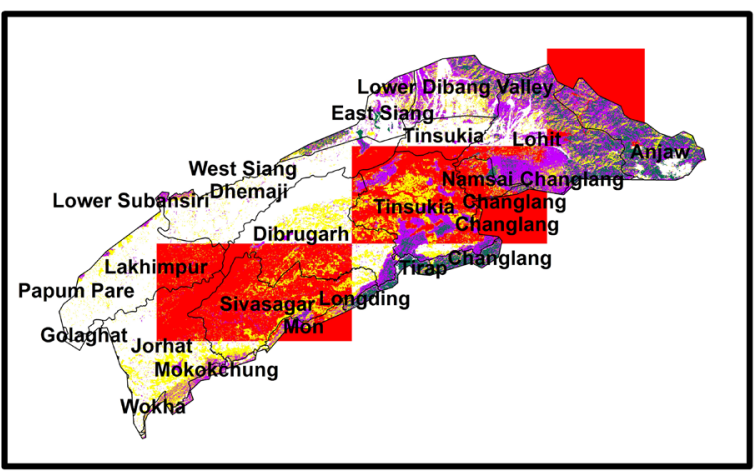

(b)

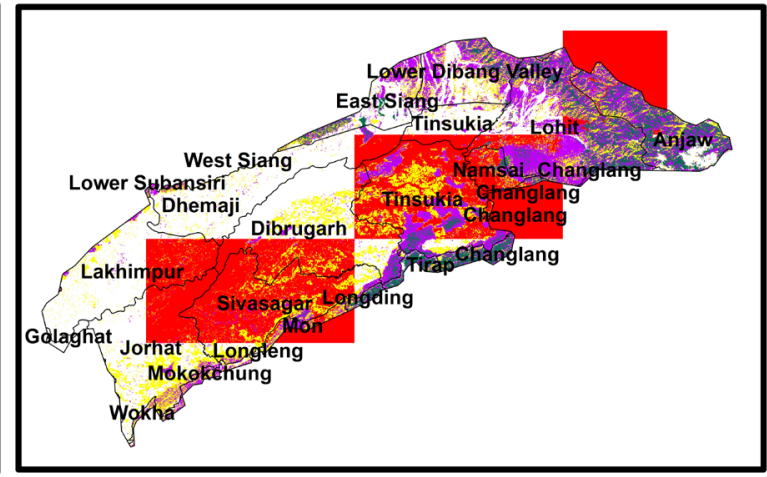

(d)

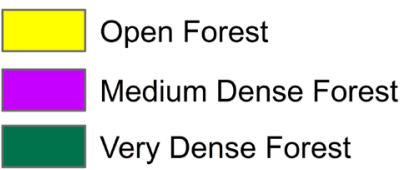

Vegetation Shift

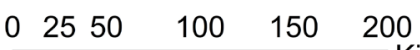

Figure 7. (a)-(d) Vegetation shifts in the long-term (2071-2100) as simulated by IBIS and LPJ under RCP 4.5 and 8.5 scenarios for the Brahmaputra river basin.

\subsubsection{NPP Change in the Mid and Long-Term under RCP 8.5}

The impact of climate change on NPP is presented in Figure 8 for the mid and long-terms under RCP8.5 as simulated by the two DGVMs. IBIS model projects increased NPP in the districts of Dibrugarh, Tinsukia, Lohit and Anjaw in the mid-term under RCP8.5. However, in the long-term under RCP8.5 the districts of Shivsagar, Dibrugarh and Lohit are projected to have increased NPP of more than $50 \%$.

LPJ projects increase in NPP in the southern part of Tinsukia and Lohit under RCP8.5 in the mid-term. There is also an NPP decrease in the districts of East Sing, Lower Dibang Valley and northern parts of Lohit in the mid-term. The long-term projections of LPJ under RCP8.5 show increased NPP (50 and more than 50\%) in the districts of Tinsukia, Lohit and Dibrugarh.

In summary, climate impact assessment using the 2 DGVMs showed that Brahmaputra river basin is least impacted in the mid-term with only 1 to 2 grid points impacted, while in the long-term 1 to 5 grid points are impacted out of a total of 10 grid points covering the basin under RCP8.5. In general, NPP is projected to increase in most of the forested grid points. 


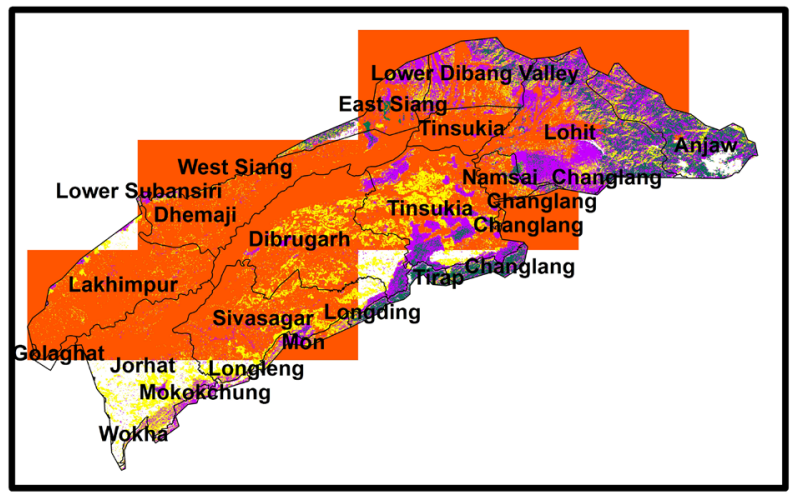

(a)

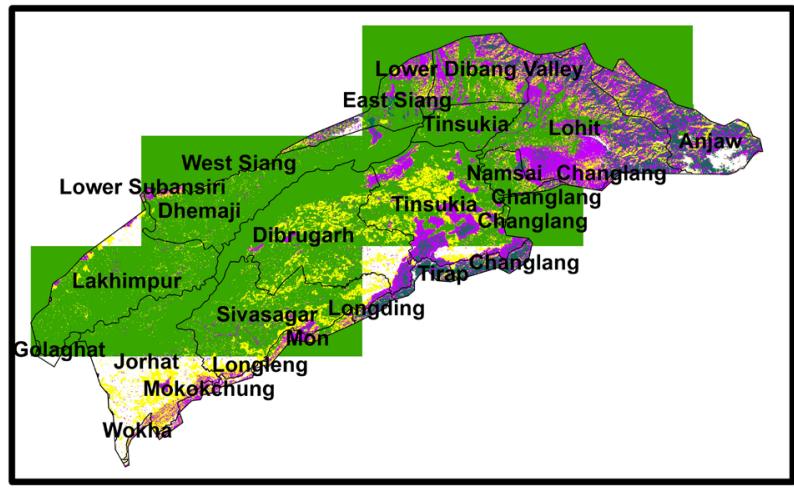

(c)
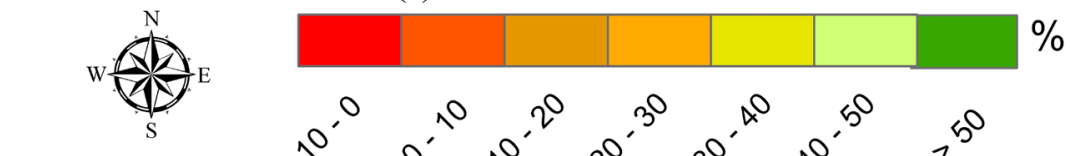

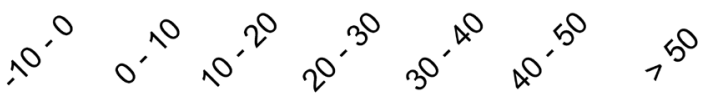

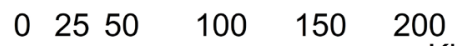

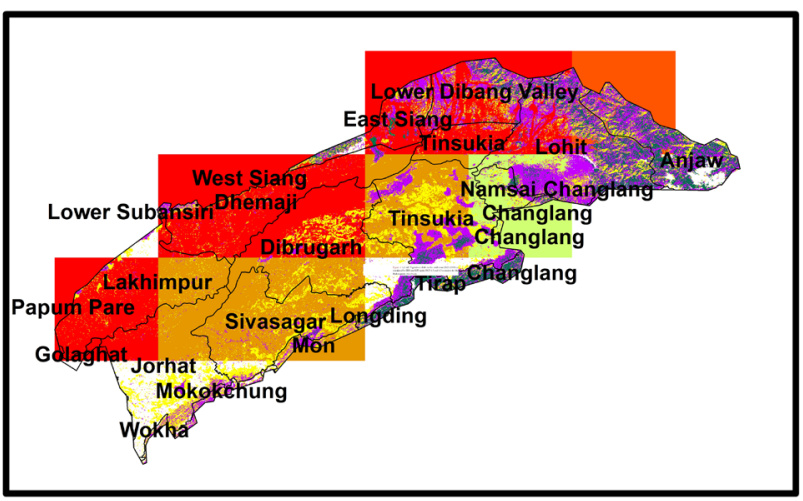

(b)

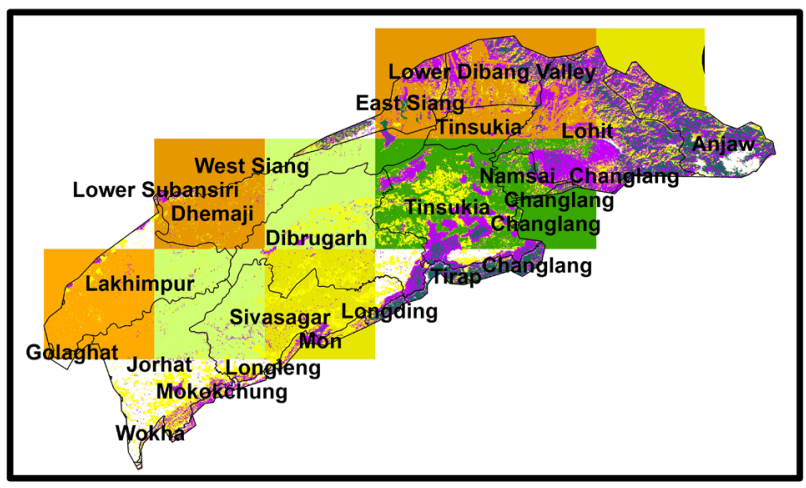

(d)

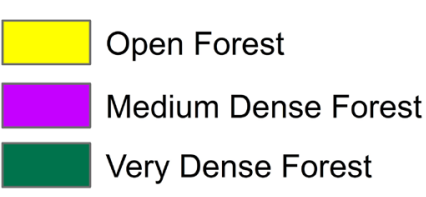

Figure 8. NPP change in the mid-term (2021-2050) and long-term (2071-2100) under RCP8.5 as simulated by IBIS and LPJ for the Brahmaputra river basin.

\subsection{Impact of Climate Change on Forest Ecosystems of Koshi River Basin}

\subsubsection{Forest Vegetation Shift under RCP 4.5 and 8.5 in the Mid-Term}

The grid points projected to undergo change in forest type in the mid-term under RCP4.5 and 8.5 as simulated by the two DGVMs are presented in Figures 9(a)-(d). IBIS model projects that only two grid points covering the districts of Solukhumbu, Dolakha and Ramechhap will undergo vegetation type shift under both RCP 4.5 and 8.5 in the mid-term. These districts are dominated by dense and sparse Conifer forests. However, LPJ projects vegetation shifts for five grids covering the districts of Siraha, Saptari, Udayapur, Sindhuli, Solukhumbu, Okhaldunga, Mahottari and Dhanusaunder RCP 4.5 and 8.5. All of these districts are dominated by dense and sparse broadleaved forests.

\subsubsection{Forest Vegetation Shift under RCP 4.5 and 8.5 in the Long-Term}

The grid points projected to undergo change in forest type in the long-term under 


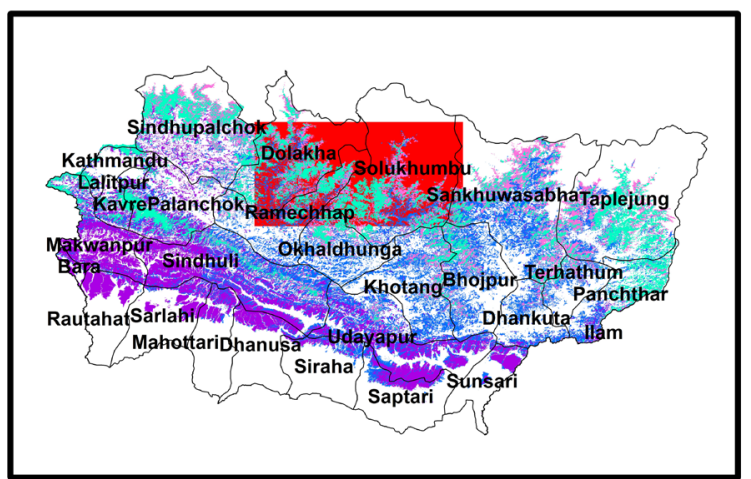

(a)

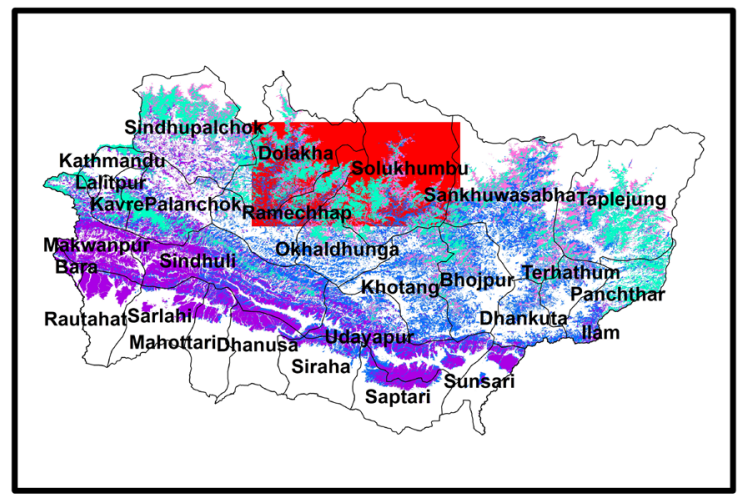

(c)

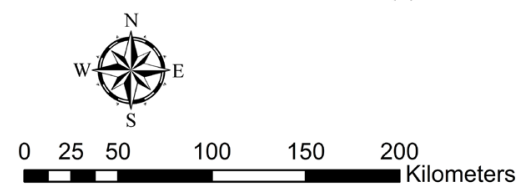

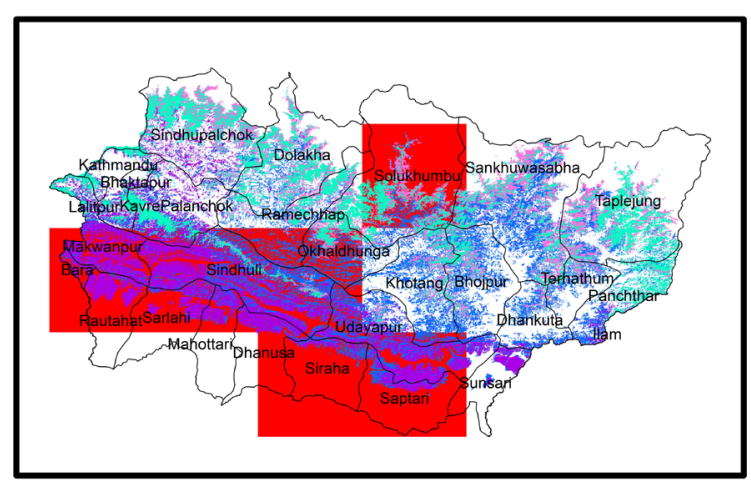

(b)

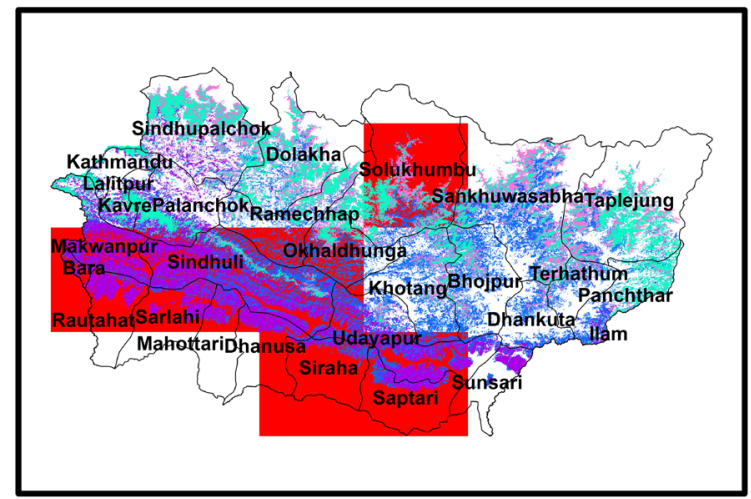

(d)

Vegetation Shift
Dense Conifer Forest

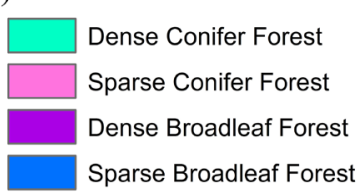

Figure 9. (a)-(d) Vegetation shifts in the mid-term (2021-2050) as simulated by IBIS and LPJ under RCP 4.5 and 8.5 for Koshi river basin.

RCP4.5 and 8.5 as simulated by the two DGVMs are presented in Figures 10(a)-(d). IBIS model projects that two grid points covering three districts namely Solukhumbu, Dolakha and part of Ramechhap are projected to be impacted under RCP 4.5, whereas five grid points covering Solukhumbu, Dolakha, Taplejung, Sankhuwasabha and part of Ramechhap and Sindhupalchok are projected to be impacted by climate change under RCP 8.5. All of these districts are dominated by dense and sparse conifer forests.

The projections of LPJ show that the districts of Siraha, Saptari, Sindhuli, Solukhumbu, Makwanpur, Bara and parts of Udayapur, Okhaldunga, Rautahat, Sarlaphi, Mahottari and Dhanusaas undergo vegetation change under both RCP 4.5 and 8.5. All of these districts are dominated by dense and sparse broadleaved forests.

\subsubsection{NPP Change in the Mid and Long-Term under RCP 8.5}

Figure 11 shows the projected change in NPP in the mid and long-terms under RCP8.5 only as simulated by the two DGVMs. Only one grid point covering Sindhupalchok is projected to experience higher percentage increase in NPP of 
about $50 \%$ to $60 \%$ under RCP 8.5 by IBIS in the mid-term. This grid point has dense and sparse conifer forest. Similarly, in the long-term NPP increase is projected for four grid points covering the districts: Kavre, southern part of Sindhupalchok, Taplejung, Bhojpur, Sankhuwasabha and Dhankuta.

LPJ projects a reduction in NPP of up to $10 \%$ for the districts Sindhupalchok, Kathmandu, Bhakatapur and Kalitpur which have dense conifer and broadleaf forests in the mid-term. NPP is projected to increase in the range of $25 \%-30 \%$ under RCP 8.5, in Eastern region of basin covering districts Kavere, Kathmandu, Dolakha and Bhakatpur under LPJ. The NPP change for Sindhupalchokas simulated by LPJ is contrary to result by IBIS. Central portion of the river basin with sparse and dense broadleaf forest is projected an increase of $10 \%$ under RCP 8.5. Taplejung and Sankhuwasabha with sparse conifer and broadleaf forest are projected to increase by $40 \%-80 \%$.

In summary, climate change is projected to impact $2-6$ grid points in the mid-term and 5 - 6 grid points in the long-term according to the 2 DGVMs.

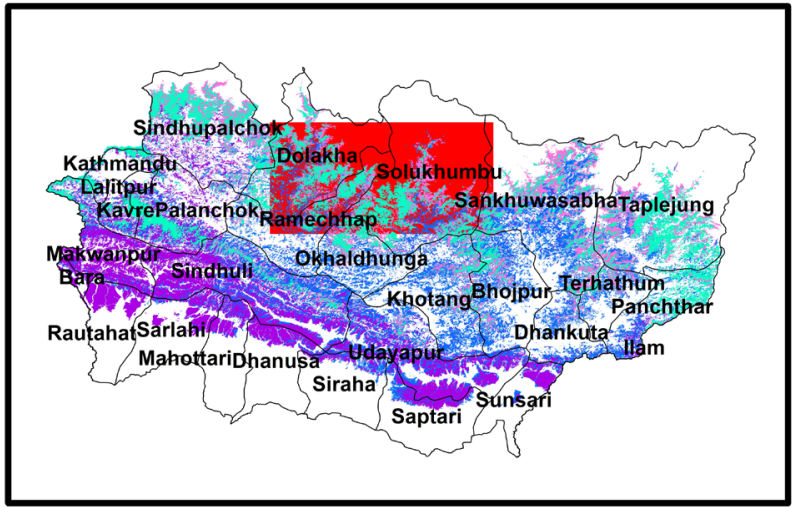

(a)

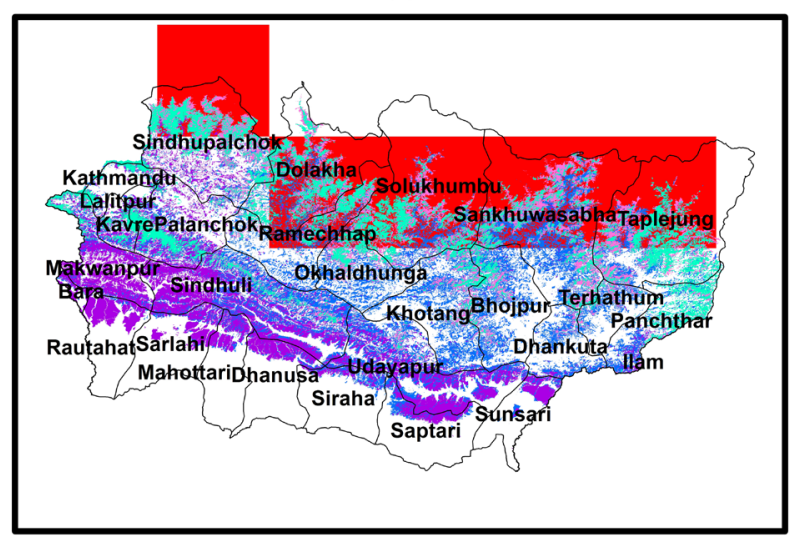

(c)

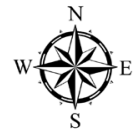

$0 \quad 25 \quad 50$

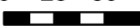

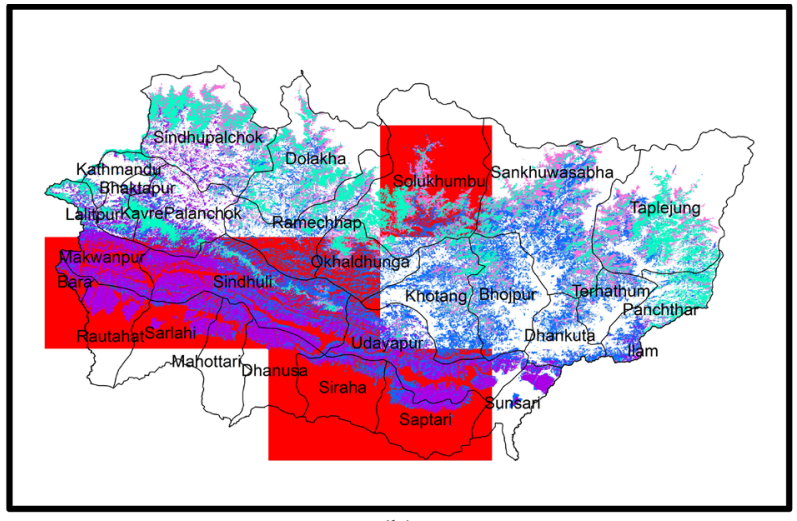

(b)

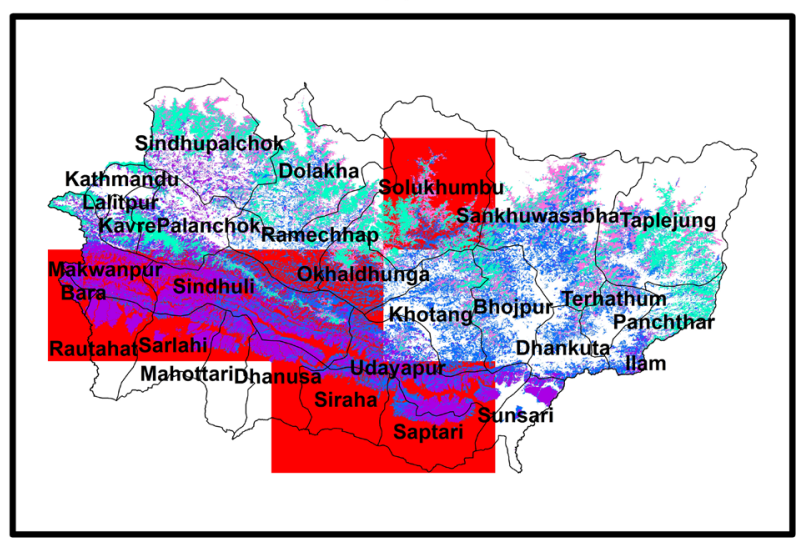

(d)

Vegetation Shift

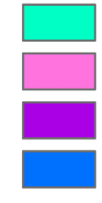

Dense Conifer Forest Sparse Conifer Forest

Dense Broadleaf Forest

Sparse Broadleaf Forest

Figure 10. (a)-(d) Vegetation shifts in the long-term (2071-2100) as simulated by IBIS and LPJ for RCP 4.5 and 8.5 for Koshi river basin. 


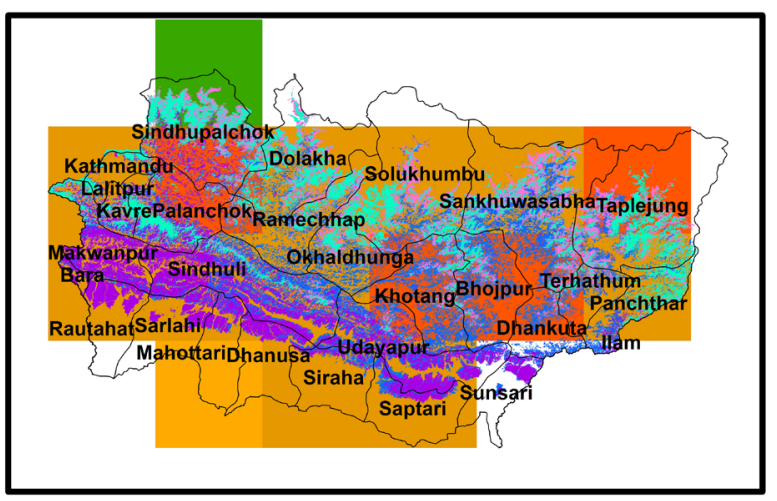

(a)

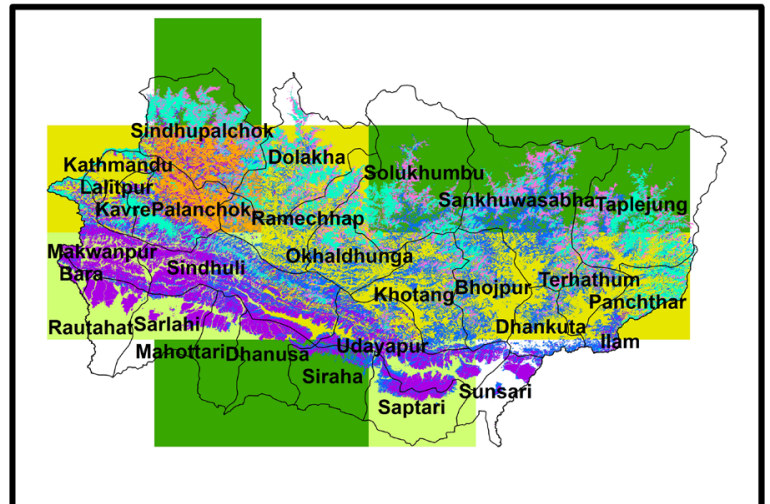

(c)

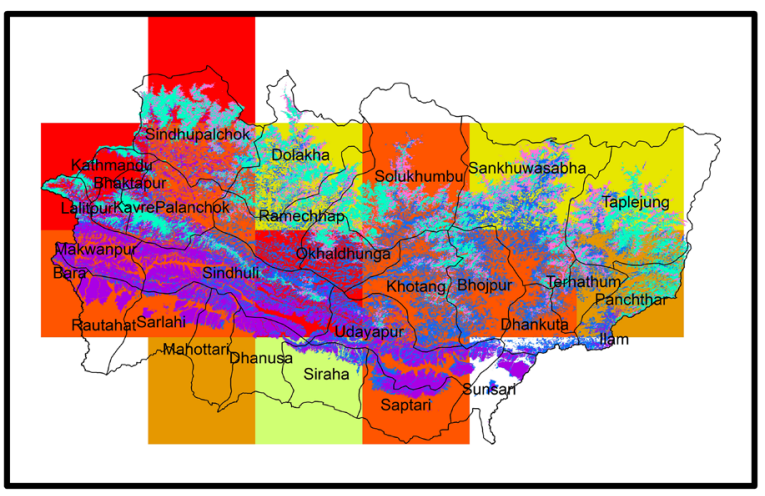

(b)

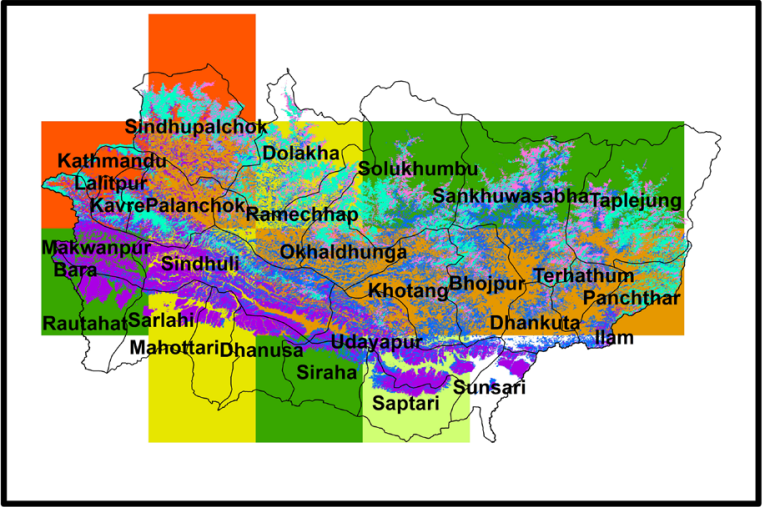

(d)
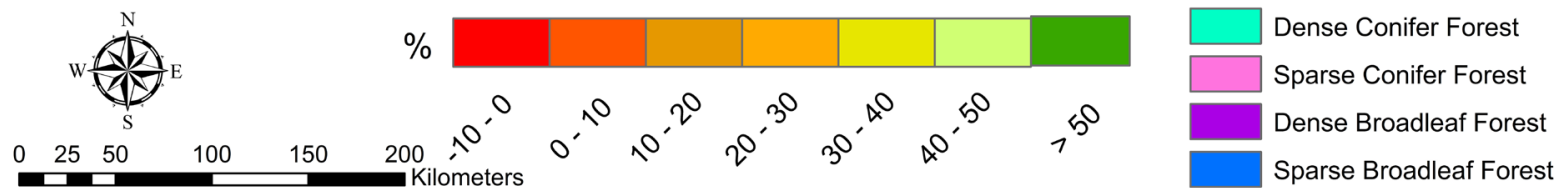

Figure 11. NPP change in the mid-term (2021-2050) and long-term (2071-2100) under RCP8.5 as simulated by IBIS and LPJ for Koshi river basin.

Further, forest vegetation shift is projected for Solukhumbu under both the DGVMs. NPP is generally projected to increase in most grid points in the mid and long-terms.

\subsection{Impact of Climate Change on Forest Ecosystems of Indus River Basin}

\subsubsection{Forest Vegetation Shift under RCP 4.5 and 8.5 in the Mid-Term}

Figures 12 (a)-(d) show the grid points projected to undergo change in forest type in the mid-term under the two RCPs as simulated by the two DGVMs. IBIS model projects that the majority of grid points covering almost all the central region of the basin to be impacted by climate change. Gilgit, Diamir, Swat, Shangla, Upper Dir, Chitral and Kohistan are the districts to be impacted under RCP 4.5 in the mid-term. According to IBIS, all the districts as projected to be impacted under RCP 4.5 are also projected to be impacted by climate change under RCP 8.5 and in addition Haripur is also projected to be impacted. As compared to IBIS, LPJ shows less number of forested grid points to be impacted 
by climate change covering mostly the southern parts of the basin. Five grid points covering Upper Dir, Swat, Shangla, Buner, Batagram, Mansehra, Abbottabad, Gilgit and Diamir are projected to be impacted by LPJ in the mid-term under both RCP4.5 and 8.5.

\subsubsection{Forest Vegetation Shift under RCP 4.5 and 8.5 in the Long-Term}

Figures 13(a)-(d) present the grid points projected to undergo change in forest type in the long-term under the two RCPs as simulated by the two DGVMs. IBIS model projections show that along with the central and eastern districts of Diamir, Gilgit, Kohistan, Upper Dir, Shangla, Swat and Chitral, two southern districts namely Haripur and Mansehra are projected to be impacted by climate change in the long-term under both the RCPs. However, LPJ projects vegetation shift in grid points having dense forest consisting of districts: Swat, Kohistan, Shangla, Mansehra, Batagram, Abbottabad, Haripur and Buner for both the RCPs. This region predominantly has dense mix and conifer forest.

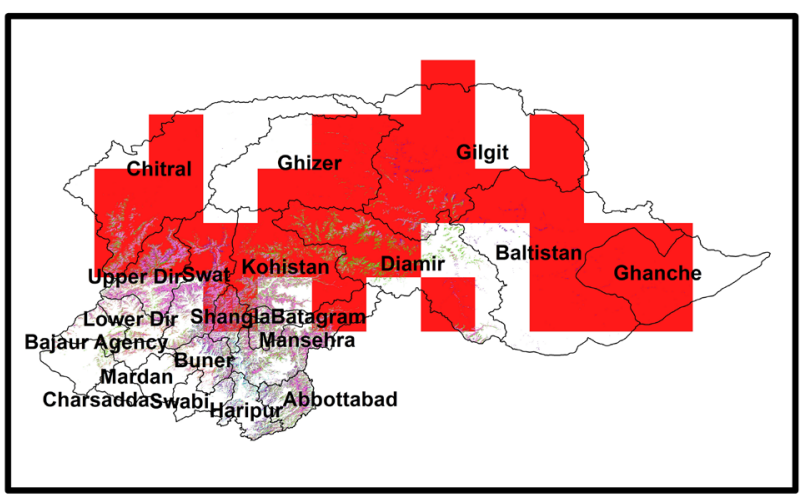

(a)

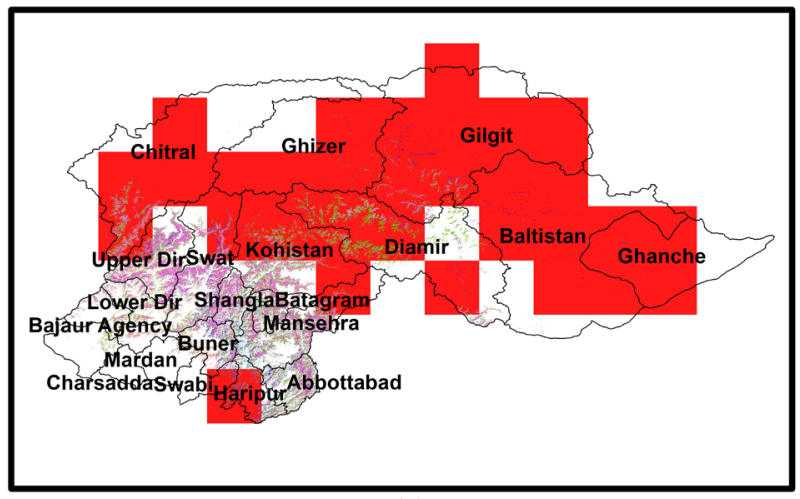

(c)

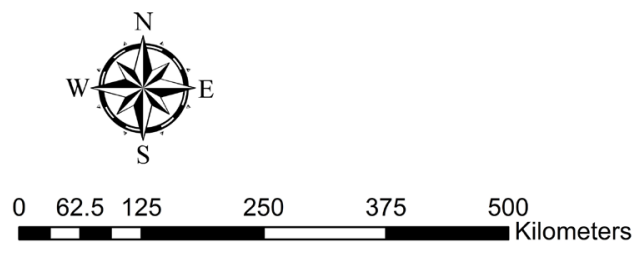

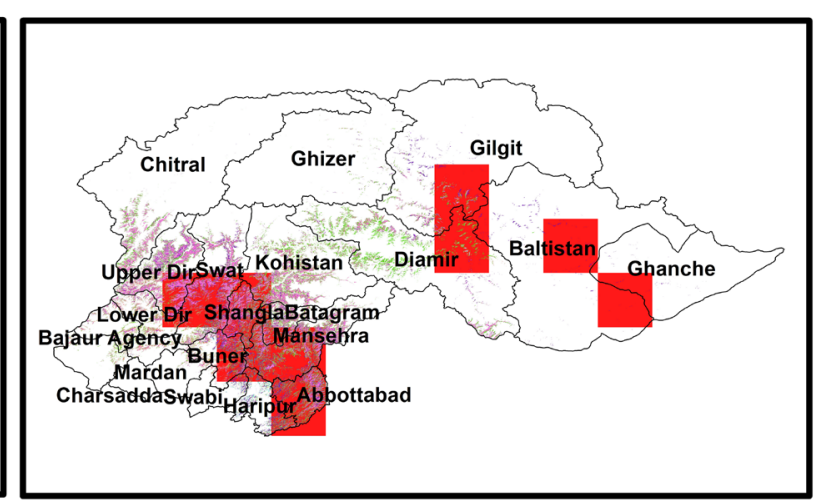

(b)

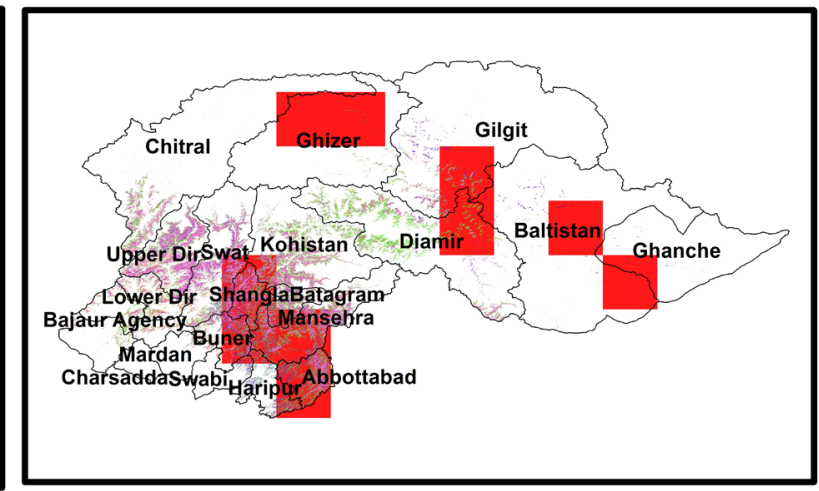

(d)

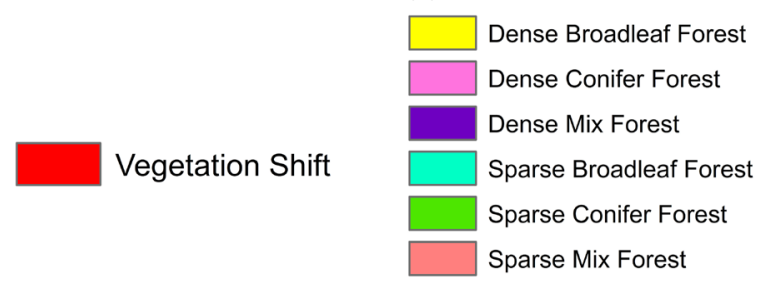

Figure 12. (a)-(d) Vegetation shifts in the mid-term (2021-2050) as simulated by IBIS and LPJ for RCP 4.5 and 8.5 for Indus river basin. 


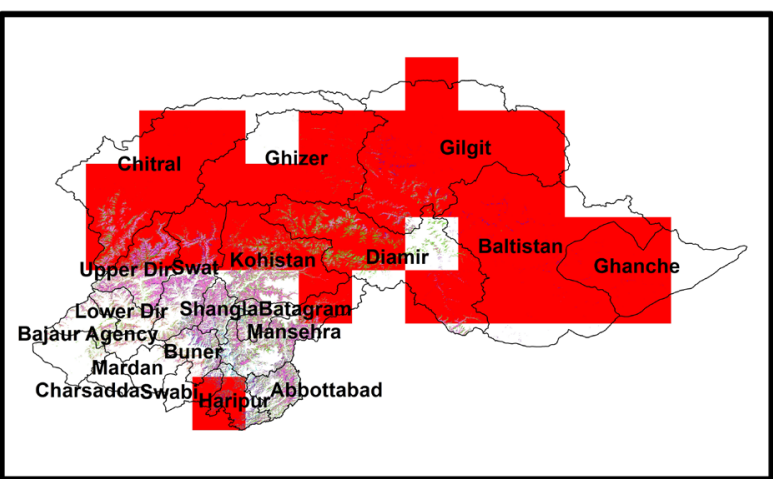

(a)

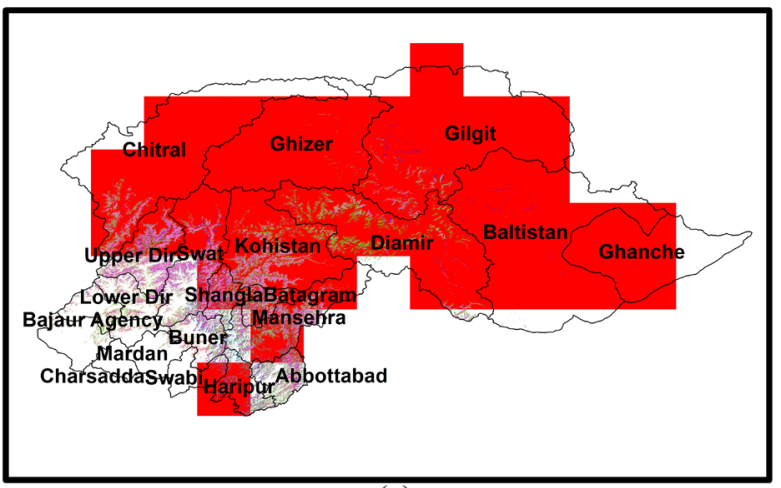

(c)

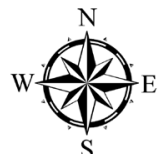

$0 \quad 62.5 \quad 125$

Kilometers

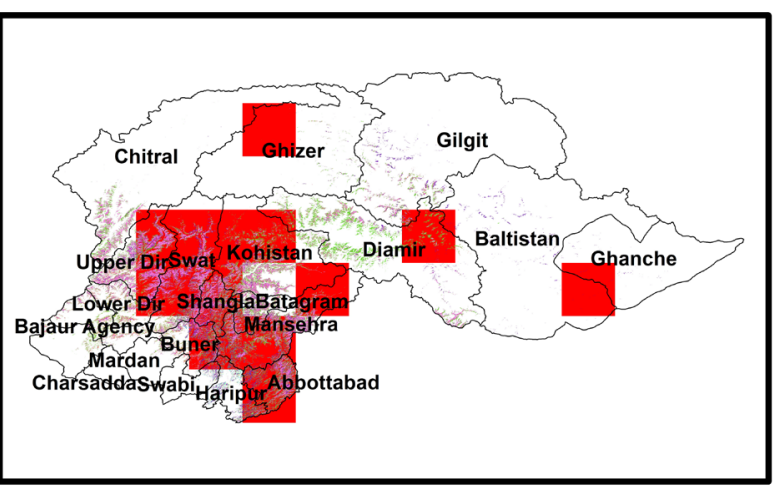

(b)

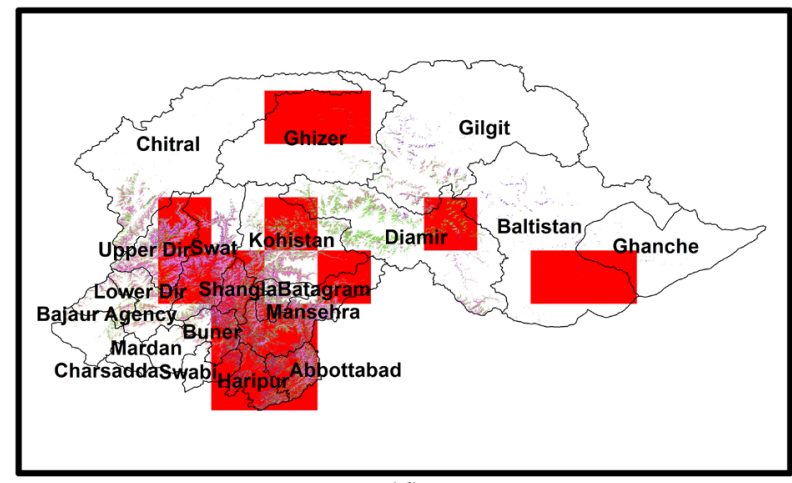

(d)

Vegetation Shift

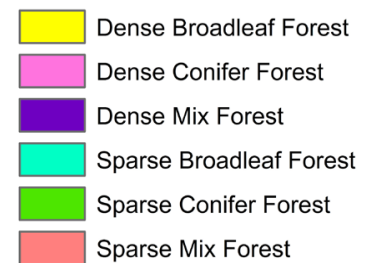

Figure 13. (a)-(d) Vegetation shifts in the long-term (2071-2100) as simulated by IBIS and LPJ for RCP 4.5 and 8.5 for Indus river basin.

\subsubsection{NPP Change in the Mid and Long-Term under RCP 8.5}

Figure 14 shows the projected change in NPP in the mid and long-terms, under RCP8.5, as simulated by the two DGVMs. IBIS model projects a decrease in NPP of about $10 \%-20 \%$ in the highly forested south western parts of the basin under RCP8.5 in the mid and long-terms. This includes the districts Mardan, Swabi, Haripur, Buner, Abbottabad, Malakand PA, Lower Dir, Mohmand Agency, which have dense conifer and mix forest. However, the districts of the central region Diamir, Swat, Kohistan, Upper Dir and Gilgit are projected to have an increase of NPP by $20 \%-100 \%$ in the mid and long-terms.

LPJ projects an increase in NPP for the entire basin area. LPJ projects $10 \%$ $30 \%$ increase in NPP in the central part of the basin covering districts of: Kohistan, Diamir, Swat, Batagram, Shangla for RCP 8.5. Further, more than $90 \%$ increase in NPP is projected in parts of Gilgit. Ghizer, Baltistan and Ghanche, which have very low forest cover. The central region with districts: Ghizer, Chitral, Kohistan and Diamir which have sparse and dense conifer forest is projected an increase of $60 \%-90 \%$. 


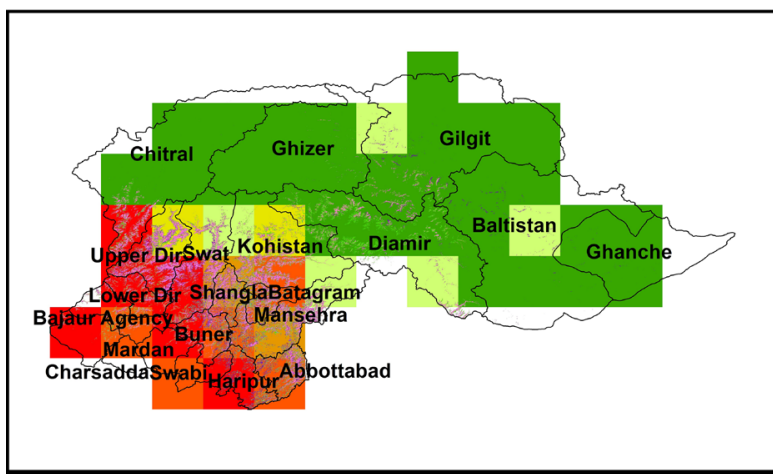

(a)

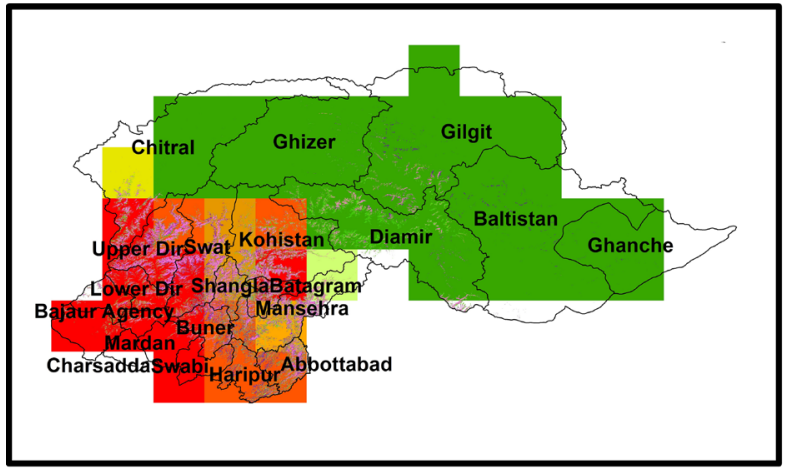

(c)

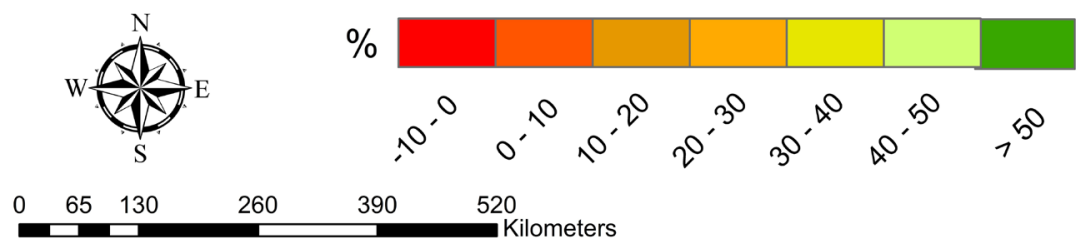

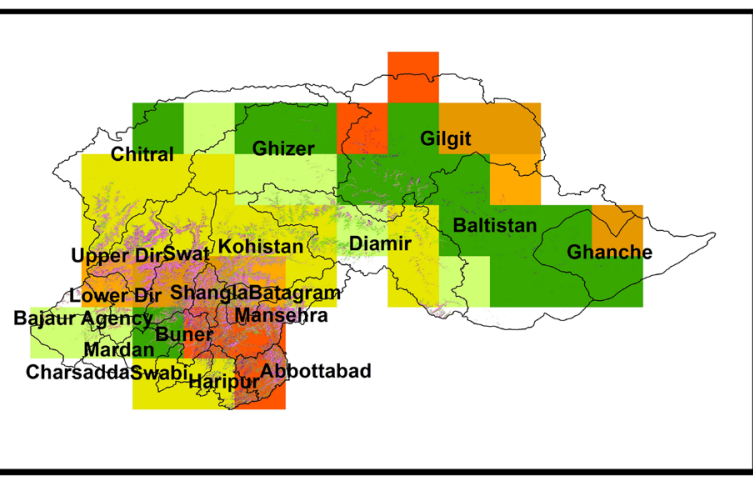

(b)

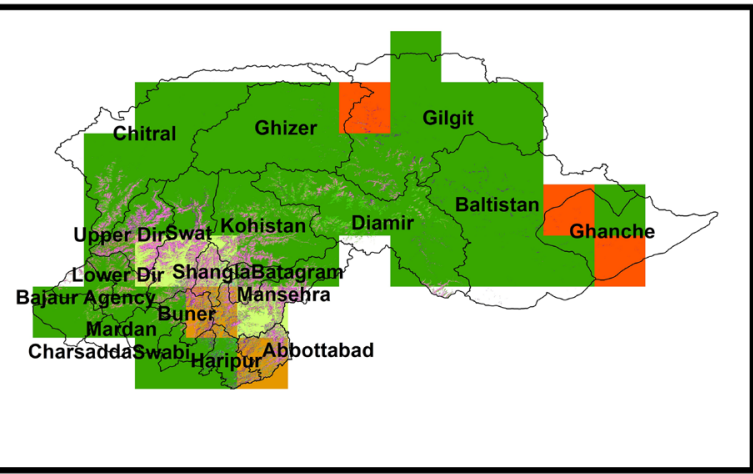

(d)

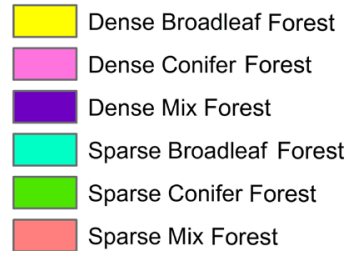

Figure 14. NPP change in the mid-term (2021-2050) and long-term (2071-2100) under RCP8.5 as simulated by IBIS and LPJ for Indus river basin.

In summary, climate change in the long-term is projected to impact largely the forested districts of South and Western districts according to LPJ while most districts except the South-western districts will be impacted by climate change according to IBIS. Further, largely the forest-dominant districts will be impacted as simulated by LPJ. NPP is projected to decrease in the forest dominated districts of south and south-western districts by IBIS, while LPJ projects an increase in NPP for the same districts.

\section{Summary and Conclusions}

In this study, impacts of climate change in terms of vegetation shifts and NPP (a measure of vegetation productivity) changes are assessed for Brahmaputra, Koshi and Indus river basins for the mid (2021-2050) and long (2071-2100) terms for RCP4.5 and RCP8.5 scenarios. Two dynamical vegetation models (DGVMs), IBIS and LPJ, have been used for this purpose. The DGVMs are driven by the ensemble mean climate projections from 5 climate models that contributed to the CMIP5 data base. The use of more than one DGVM helps to assess the un- 
certainty, robustness and reliability in model-based estimates of impacts while the ensemble mean of climate projections from 5 climate models helps to narrow down the uncertainty in climate change projections. The issue of uncertainty has been addressed by use of more than one DGVM as regions which are projected to undergo change under both models could be the regions for implementing adaptation interventions, thereby increasing reliability and robustness of projections in change.

Forests are mostly prevalent in the northern, middle and southern part of the Brahmaputra, Koshi and Indus river basins, respectively. Tropical semi-evergreen forests dominate the Brahmaputra basin, Koshi basin is dominated by dense broadleaved forests and Indus basin is dominated by dense conifer forests. While both DGVMs project vegetation shifts in the forests areas of the basins, there are differences in vegetation shifts projected by IBIS and LPJ. This may be attributed mainly to differences in representation of various physical and biological processes in the models and in the number of vegetation types (Plant Functional Types) defined and simulated in the two models. However, there is some agreement in NPP changes as projected by both IBIS and LPJ, with IBIS mostly projecting larger increase in NPP for the future scenarios. For the high emission RCP8.5, NPP is projected to change by $-6 \%$ to $15 \%$ in the forested areas of the Brahmaputra basin in the mid-term and by $10 \%-45 \%$ in the long-term. For the Koshi river basin, vegetation productivity is projected to change by $-10 \%$ to $20 \%$ in the mid-term and by $10 \%-35 \%$ in the long-term in the forested areas. In the case of Indus basin, DGVMs project NPP change is about $-10 \%$ to $10 \%$ in the mid-term and $-20 \%$ to $20 \%$ in long-term in the forests areas of the basin. The increased future levels of $\mathrm{CO}_{2}$ and the consequent $\mathrm{CO}_{2}$ fertilization are primarily responsible for increased terrestrial vegetation productivity. In higher altitudes, increased length of growing season should also play a major role in enhancing NPP since ecosystems at higher altitudes are presently temperature-limited. Further increases in annual mean rainfall are also likely to result in increased NPP. However, caution should be exercised because future land cover change and nutrient limitations are not represented in both IBIS and LPJ. Both land cover change and nutrient limitation could reduce the increase in NPP that is simulated in our study.

The impact of climate change on forest ecosystems and biodiversity could be long-term and irreversible. Forest ecosystems are very critical for biodiversity, watershed protection and livelihoods of forest dependent communities especially in the Himalayan river basins. Thus it is necessary to make a reliable and robust assessment of the impacts of climate change on forest ecosystems and biodiversity. In the present DGVM based assessment, vegetation shifts are projected and further declines in vegetation productivity in several grid points of the forested regions of the three major river basins are also projected. Use of more climate models for climate projections and more DGVMs is recommended in the future to reduce the uncertainty and increase the confidence in assessment of the impacts of climate change on the forests. Further, there are limitations with respect 
to DGVMs for species level assessment of the impacts of climate change: DGVMs only assess the shifts in the forest types. We have assumed in this study that any shift in the forest types indicates the non-suitability of the future climate to the existing forest types and biodiversity, leading to potential forest dieback and short-term loss of biodiversity and biomass production.

We have assessed only NPP changes because models generally have some amount of bias in simulating NPP and hence it is normally a better practice to investigate only the changes. When baseline NPP is subtracted from future NPP, it is assumed that the biases get subtracted out between two model simulations and the signal (trend) is intact. Therefore, only the changes in NPP are investigated in this study. One improvement to our present analysis would be to compare the \% change in NPP in grids that undergo vegetation shifts to those where there is no vegetation shift. Such an analysis would identify if larger NPP changes are associated with vegetation shifts.

Despite the uncertainties with respect to climate change projections at watershed or sub-basin level and the varying impact assessment from different DGVMs, it is necessary to assess vulnerability of the forest ecosystems and forest dependent communities and to develop and implement resilience or adaptation measures. The next step should be to estimate the "Current Vulnerability" of the forest ecosystems and forest dependent communities to assess the inherent vulnerability of the forest ecosystems as determined by the current state of forests and the stressors on the forests following the steps suggested by Sharma et al. (2015). IPCC (2014) has concluded that climate change combined with the non-climate stressors will exacerbate the impacts of climate change. Hence, fragmented, degraded and disturbed forests are likely to be more vulnerable to climate change impacts.

In the absence of more DGVMs (than the IBIS and LPJ models), assessment of the vulnerability and designing of the adaptation strategies could be undertaken for all the forested grid points where there is consistency in changes projected by both IBIS and LPJ models. Based on the current vulnerability assessment, the most vulnerable forest types and districts could be identified and ranked for adaptation interventions.

\section{Implications for Further Research and Forest Management}

The coming into force of the recent Paris agreement under the United Nations Framework Convention on Climate Change (UNFCCC) has again drawn attention to the urgent need for countries to take ambitious efforts to combat climate change and adapt to its effects. Forests and terrestrial ecosystems, especially in the Himalayan region, are increasingly assuming a more prominent role both as important carbon sinks and as an adaptation option. Forest ecosystems are critical for biodiversity, watershed protection, and the livelihoods of forest dependent communities, especially in the Himalayan river basins and it is impor- 
tant to make reliable and robust assessments of the projected impacts on them of climate change.

In the Himalayas and the regions downstream, there is a large dependence on climate-sensitive sectors such asagriculture, forests, and fisheries. Forest-dependent communities form one of the poorest sections of society and the adverse impacts on them of climate change are likely to be compounded by a range of factors including limited institutional linkages, under developed markets, absence of technology-transfer pathways, and lack offinancial resources. In the present assessment, analysis suggests that climate change represents a threat to many forested grids in the Himalayan region as it will lead to shifts in the type of vegetation, with the future climate unsuitable for the existing forest types and biodiversity. The fragmented and isolated forests in low biodiversity areas are especially vulnerable to the impacts of vegetation shifts due to their limited dispersal, germination, and migration capabilities. To some extent, climate change also presents an opportunity in some forested grids in the form of increased net primary productivity due to the effect of increased carbon dioxide fertilization. However, the scenario of increased productivity could be threatened by lack of adequate water and other nutrients in a warming climate, as well as the projection of vegetation shifts, especially in low biodiversity, disturbed, and fragmented habitats.

Development and implementation of adaptation strategies and practices for climate change in the forest sector in the Himalayan region will require long gestation periods, and years of research and development, institutional building, and education. To enable this, it is important to have as much information about the likely future scenario as possible. However, there are a number of adaptation practices that could be incorporated in afforestation and reforestation projects to help restore and maintain forest functions and address and pre-empt the potential impacts of climate change. They include:

- Promotion of regeneration of native species in degraded natural forest lands through protection and naturalregeneration to reduce vulnerability to the changing climate

- Promotion of multi-species plantation forestry incorporating native species in place of mono-culture plantation of exotic species to reduce vulnerability

- Adoption of short-rotation species in commercial or industrial forestry to facilitate adaptation to any adverse impacts of climate change

- Incorporation of silvicultural practices such as sanitation harvest and increased thinning to reduce the occurrence of pests and diseases

- Incorporation of fire protection measures to reduce the vulnerability of forests to fire hazards resulting from warming accompanied by droughts

- Implementation of soil and water conservation measures to reduce the adverse impacts of drought on forestgrowth

- Use of soil and water conservation as a key adaptation practice for reducing vulnerability; the practice also reduces carbon loss from soils and enhances 
soil carbon density by increasing the biomass growth rate of forests, plantations, or grassland

- Planting of drought-resistant varieties or clones to reduce the vulnerability of tree and grass species to droughts and water stress, and also increase carbon sequestration rates

- Enhancing of soil organic matter content through organic manure to increase the moisture retention and soilfertility, both to reduce the vulnerability to drought and moisture stress and to increase carbon sequestration rates of trees and grasses

- Implementation of forest and biodiversity conservation through halting deforestation, expanding protected areas, and adopting sustainable harvest practices. This is a vital adaptation strategy to reduce the vulnerability of forest ecosystems. Most importantly, forest conservation activities in the region should be designed such that these activities reduce the fragmentation and degradation of existing forests. Anticipatory planting and assisted natural migration through transplanting of plant species could also be considered.

\section{Acknowledgements}

This study was jointly carried out by the Indian Institute of Science (IISc) and International Centre for Integrated Mountain Development (ICIMOD) under the Himalayan Climate Change Adaptation Program (HICAP). HICAP is implemented jointly by ICIMOD, CICERO and Grid-Arendal in collaboration with local partners and is funded by the Ministry of Foreign Affairs, Norway and Swedish International Development Agency (SIDA) and core funds of ICIMOD contributed by the governments of Afghanistan, Australia, Austria, Bangladesh, Bhutan, China, India, Myanmar, Nepal, Norway, Pakistan, Switzerland, and the United Kingdom. We equally acknowledge financial support from Norwegian Research Council and CICERO. The views and interpretations in this publication are those of the author(s) and should not be ascribed to ICIMOD, IISc or their donors.

\section{References}

[1] Kirschbaum, M.U.F., Cannell, M.G.R., Cruz, R.V.O., Galinski, W. and Cramer, W.P. (1996) Climate Change Impacts on Forests. In: Watson, R.T., Zinyowera, M.C., Moss, R.H. and Dokken, D.J., Eds., Climate Change 1995. Impacts, Adaptation and Mitigation of Climate Change: Scietific-Technical Analyses, Cambridge University Press, Cambridge, 95-129.

[2] Walter (1985) Vegetation Systems of the Earth and Ecological Systems of the Geo-Biosphere. Springer-Verlag, Berlin. https://doi.org/10.1007/978-3-642-96859-4

[3] IPCC (2007) Climate Change 2007: Working Group II Report: Impacts, Adaptation and Vulnerability. WMO and UNEP, Geneva IPCC (2012) Managing the Risks of Extreme Events and Disasters to Advance Climate Change Adaptation. A Special Report of Working Groups I and II of the Intergovernmental Panel on Climate Change, Cambridge University Press, Cambridge.

[4] Miles, L.J. (2002) The Impact of Global Climate Change on Tropical Forest Biodi- 
versity in Amazonia. Dissertation, University of Leeds, Leeds.

[5] McClean, C.J., Lovett, J.C., Kuper, W., Hannah, L., Sommer, J.H., Barthlott, W., Termansen, M., Smith, G.E., Tokamine, S. and Taplin, J.R.D. (2005) African Plant Diversity and Climate Change. Annals of the Missouri Botanical Garden, 92, 139-152.

[6] IPCC (2014) Climate Change 2014: Impacts, Adaptation, and Vulnerability. Part A: Global and Sectoral Aspects. Contribution of Working Group II to the Fifth Assessment Report of the Intergovernmental Panel on Climate Change, Cambridge University Press, Cambridge, and New York, 1132 p.

[7] Jagmohan, S., Upgupta, S., Kumar, R., Chaturvedi, R.K., Bala, G. and Ravindranath, N.H. (2017) Assessment of Inherent Vulnerability of Forests at Landscape Level: A Case Study from Western Ghats in India. Mitigation and Adaptation Strategies for Global Change, 22, 29-44. https://doi.org/10.1007/s11027-015-9659-7

[8] Gopalakrishnan, K., Jayaraman, M., Bala, G. and Ravindranath, N.H. (2011) Climate Change and Indian Forests. Current Science, 101, 348-355.

[9] Chaturvedi, R.K., Ranjith, G., Mathangi, J., Govindasamy, B., Joshi, N.V., Sukumar, R. and Ravindranath, N.H. (2010) Impact of Climate Change on Indian Forests: A Dynamic Vegetation Modeling Approach. Mitigation and Adaptation Strategies for Global Change, 16, 119-142. https://doi.org/10.1007/s11027-010-9257-7

[10] Kucharik, C.J., Foley, J.A., Delire, C., Fisher, V.A., Coe, M.T., Lenters, J., Young-Molling, C., Ramankutty, N., Norman, J.M. and Gower, S.T. (2000) Testing the Performance of a Dynamic Global Ecosystem Model: Water Balance, Carbon Balance and Vegetation Structure. Global Biogeochemical Cycles, 14, 795-825. https://doi.org/10.1029/1999GB001138

[11] Foley, J.A., Prentice, I.C., Ramankutty, N., Levis, S., Pollard, D., Sitch, S. and Haxeltine, A. (1996) An Integrated Biosphere Model of Land Surface Processes, Terrestrial Carbon Balance, and Vegetation Dynamics. Global Biogeochemical Cycles, 10, 603-628. https://doi.org/10.1029/96GB02692 